\title{
Attitudes Toward Help Seeking Among Depressed and Non- depressed Postpartum Women
}

\author{
Terri L. Liberto \\ West Virginia University
}

Follow this and additional works at: https://researchrepository.wvu.edu/etd

\section{Recommended Citation}

Liberto, Terri L., "Attitudes Toward Help Seeking Among Depressed and Non-depressed Postpartum Women" (2011). Graduate Theses, Dissertations, and Problem Reports. 4745.

https://researchrepository.wvu.edu/etd/4745

This Dissertation is protected by copyright and/or related rights. It has been brought to you by the The Research Repository @ WVU with permission from the rights-holder(s). You are free to use this Dissertation in any way that is permitted by the copyright and related rights legislation that applies to your use. For other uses you must obtain permission from the rights-holder(s) directly, unless additional rights are indicated by a Creative Commons license in the record and/ or on the work itself. This Dissertation has been accepted for inclusion in WVU Graduate Theses, Dissertations, and Problem Reports collection by an authorized administrator of The Research Repository @ WVU.

For more information, please contact researchrepository@mail.wvu.edu. 
Attitudes Toward Help Seeking Among Depressed and Non-depressed Postpartum Women

Terri L. Liberto, MSN, RN

\title{
Dissertation submitted to the \\ School of Nursing \\ at West Virginia University
}

in partial fulfillment of the requirements

for the degree of

\author{
Doctor of Philosophy in Nursing \\ in \\ Nursing
}

\author{
Cynthia Armstrong Persily, PhD, RN, FAAN, Chairperson \\ Stacey Culp, PhD \\ Nan Leslie, PhD, RN \\ Susan G. Poorman, PhD, RN, CNS-BC, ANEF \\ Irene Tessaro, DrPH, RN \\ School of Nursing
}

Morgantown, West Virginia 2011

Keywords: Postpartum, Postpartum Depression, Help Seeking, Pediatric Setting/Pediatrician, Pediatric Nurse Practitioner

Copyright 2011 Terri L. Liberto 


\section{ABSTRACT \\ Attitudes Toward Help Seeking Among Depressed and Non-depressed Postpartum Women Terri L. Liberto, MSN, RN}

Background: Postpartum depression is a serious mood disorder that can have negative effects on the new mother and her infant. Postpartum depression affects $10-15 \%$ of all women after childbirth. A majority of women with postpartum depression do not seek help from any source. Purpose: The purpose of this study is to examine the relationship between attitudes toward help seeking and actual help seeking in postpartum women with and without depressive symptoms. Method: A convenience sample of 130 postpartum women from northwestern Pennsylvania completed the Postpartum Depression Screening Scale (PDSS) and the Attitudes Toward Seeking Professional Psychological Help Short Form (ATSPPH-SF).The relationship between help seeking attitudes, presence of depressive symptoms, and actual help seeking was examined using quantitative analysis. Results: In this sample of postpartum women, approximately $50 \%$ reported minor or major depressive symptoms. Postpartum women with depressive symptoms had more negative attitudes toward seeking professional help than women without depressive symptoms. Postpartum women with depressive symptoms that sought help had more positive help seeking attitudes than women with depressive symptoms that did not seek help since the birth of their infant. Presence of depressive symptoms significantly predicted the help seeking attitudes in this sample of women. Conclusion: Given the significant impact of postpartum depression on maternal and infant outcomes, it is imperative to be consistent and thorough in detecting and treating postpartum depression. Since a majority of women with depression do not seek help, it is important to predict which postpartum women have attitudes that hinder professional help seeking. 


\section{Dedication}

I dedicate this dissertation first to my grandfather, Thomas L. Corey (1907-1981), who received his Master's degree in engineering from Carnegie University despite great adversity and proceeded to teach engineering at a local university. He was very supportive and encouraged me to continue my education. I hope he is looking down on me and sending a nod of approval for taking his advice! I would also like to dedicate this to my son, Shawn. He is my proudest accomplishment and I thank him for his sense of humor, love, and support through the last 11 years of education. He was the only Kindergarten student that knew what a Master's degree was! Now, as he graduates with a diploma from high school and I graduate with a PhD from West Virginia University, I hope he recognizes and appreciates the value of advanced education and the hard work involved to achieve one's goals. Make your own path in this world, be passionate about all you do, and always find the sunshine in your day! 


\section{Acknowledgements}

I would never have been able to complete this dissertation without the guidance of my committee members, help from my friends, and support from my family. I would like to first thank my parents for their never ending love and support throughout my many years of education. They were always there to take Shawn to and from his school activities and to deliver a dinner or two for my hungry family while I was working on the computer. I feel like this degree should have their names on it too! To my dear friend, Stephanie, for knowing and understanding when I needed help before I ever asked for it! She always set time aside to share my concerns or reduce my anxiety about my writing. Her friendship is priceless! I would also like to thank members of my committee for their time and commitment in the development of this dissertation. I would like to express my deepest gratitude to my chairperson, Dr. Cynthia A. Persily, for her guidance, caring and patience throughout this research process. I am grateful for the many discussions that clarified my thinking as I completed each chapter. I would also like to thank Dr. Susan G. Poorman, for being a great mentor and friend, who has had an enormous impact on my present dissertation and a lasting influence on the type of nursing instructor I am today. I thank Dr. Stacey Culp for her patience, support, and guidance in entering and analyzing my statistical data. Your guidance clarified and organized my thinking so that I could proceed. I thank Dr. Nan Leslie for her assistance with my dissertation and her patience and support when I was ambivalent and so unsure of my progress. Her kind words of encouragement inspired me to continue and complete this dissertation. Last but not least, I would like to thank Dr. Irene Tessaro, for her help in developing my model and incorporating it into my research. I am grateful for her expertise and experience with the model in her own dissertation! Certainly I have not progressed through the last five years alone and I thank everyone who has helped me to achieve my goals. 


\section{Table of Contents}

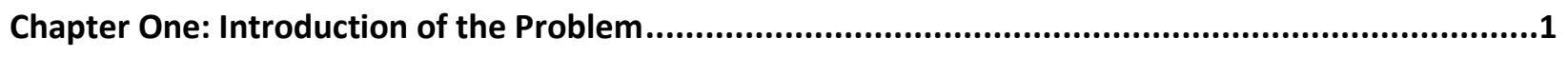

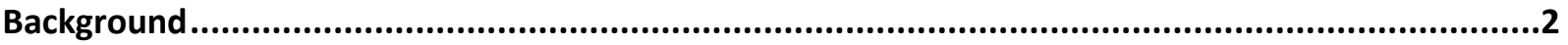

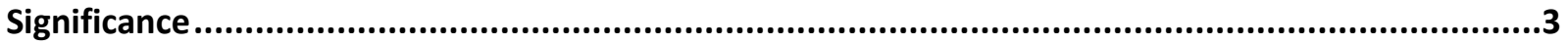

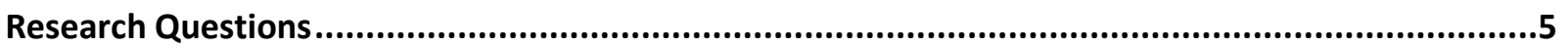

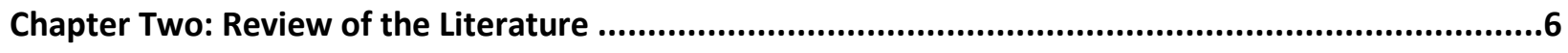

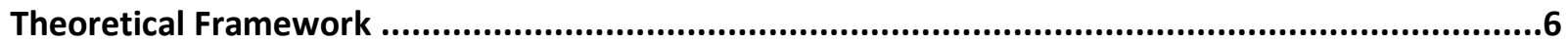

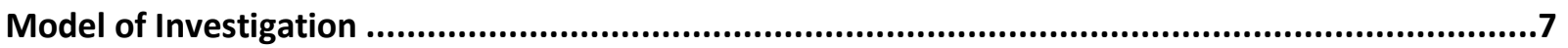

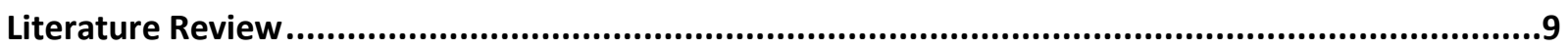

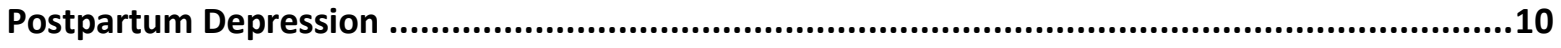

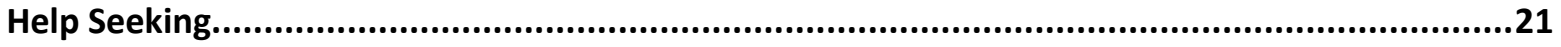

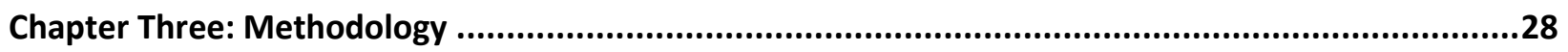

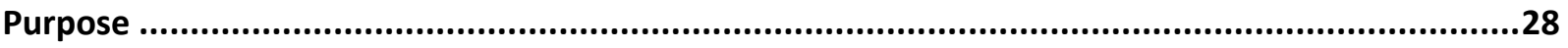

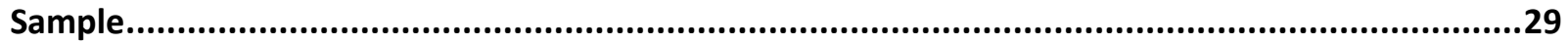

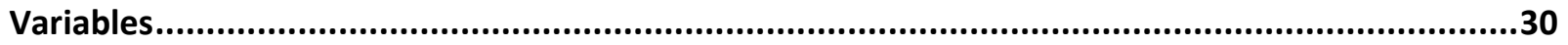

Postpartum Depression .....................................................................................................30

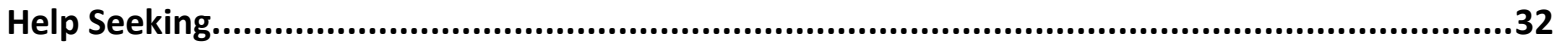

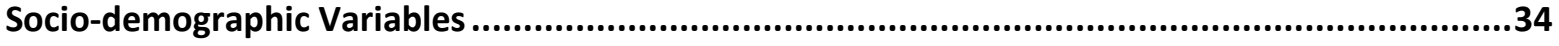

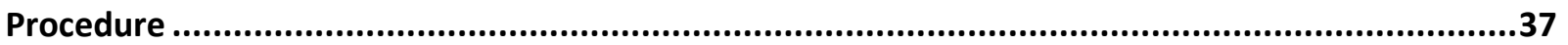

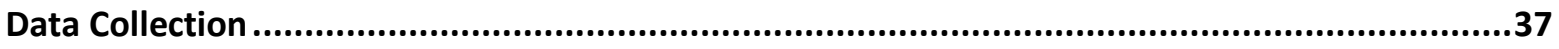

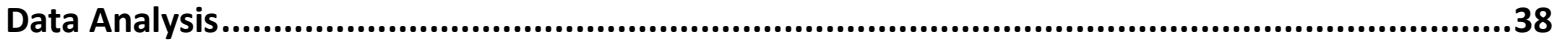

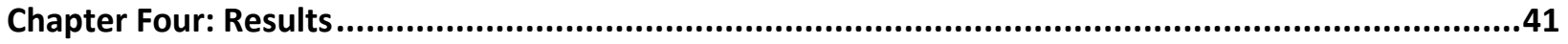

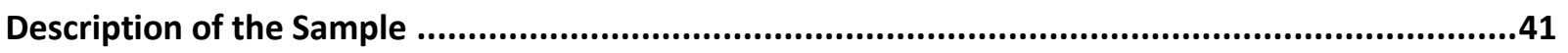

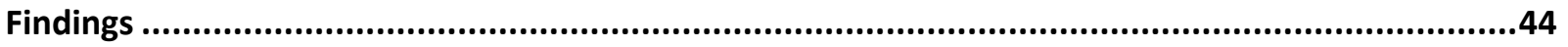

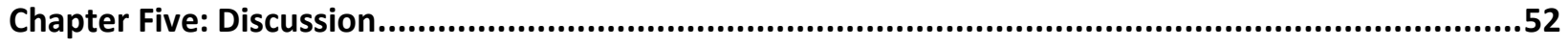

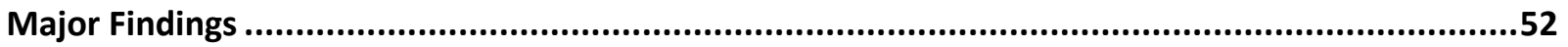

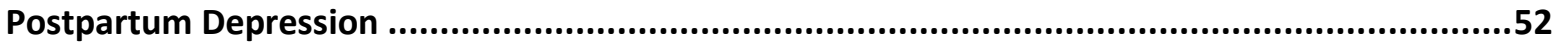

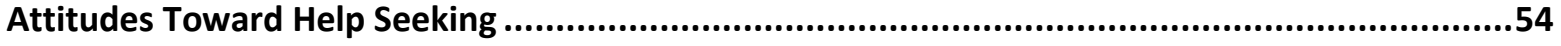

Relationship of Demographic Variables, presence of depressive symptoms, and ATSPPH-SF scores

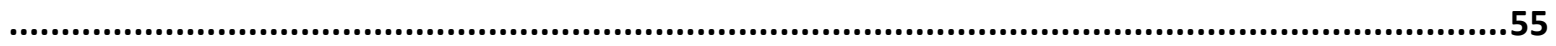

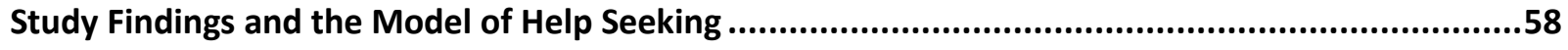




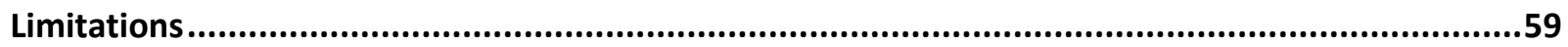

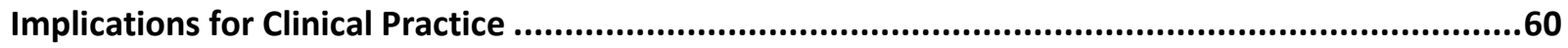

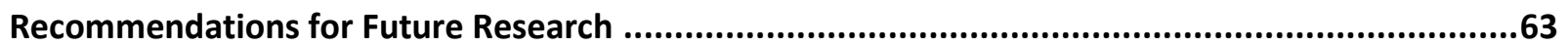

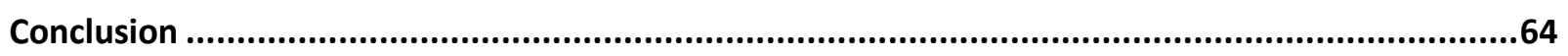

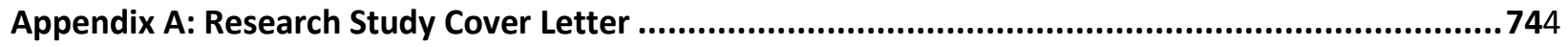

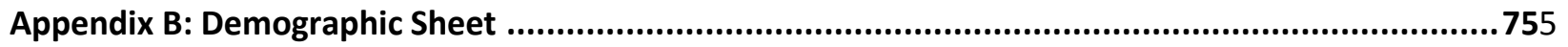

Appendix C: Postpartum Depressive Screening Scale (PDSS) ......................................................766

Appendix D: Attitudes Toward Seeking Professional Psychological Help Short Form .........................77

Appendix E: Pospartum Depression Support Group List..............................................................788

Appendix F: Normal P-P Plot of Regression Standardized Residual................................................799

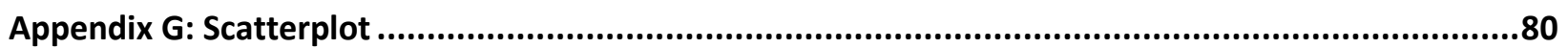




\section{LIST OF TABLES}

Table 1: Sample Demographics.

Table 2: Presence of Depressive Symptoms 45

Table 3: Differences in Attitude Scores between Postpartum Women with and without Depressive Symptoms

Table 4: Differences in Attitude Scores between Postpartum Women with Depressive Symptoms That

Seek Help and Those that do Not Seek Help..................................................................................47

Table 5: Inter-Correlation for Socio-demographic Variables, PDSS Scores, and ATSPPH-SF Scores.......49

Table 6: Multiple Regression Analysis for Variables Predicting Attitudes Toward Help Seeking...........51 


\section{LIST OF FIGURES}

Figure 1: Conceptual Model of Help Seeking in Postpartum Women .................................................8 


\section{APPENDICES}

Appendix A: Research Study Cover Letter .74

Appendix B: Demographic Sheet..

Appendix C: Postpartum Depression Screening Scale (PDSS).

Appendix D: Attitudes Toward Seeking Professional Psychological Help

Short Form (ATSPPH-SF)..

Appendix E: Postpartum Depression Support Group List.

Appendix F: Normal P-P Plot of Regression Standardized Residual..

Appendix G: Scatterplot

.80 


\section{Chapter One: Introduction of the Problem}

Postpartum depression affects $10-15 \%$ of all women after childbirth. The symptoms usually occur after discharge from the hospital. Women often lack the knowledge to recognize the symptoms of depression and fail to seek help for the condition (Holopainen, 2002). A majority of women with postpartum depressive symptoms do not seek help from any source (McGarry, Kim, Sheng, Egger, \& Baksh, 2009). Help seeking behavior for postpartum depression is influenced by a variety of factors including recognition of the problem, available resources, adequate social support, perceived stigma, and attitudes toward help seeking (Goodman, 2009; McCarthy \& McMahon, 2008; Riecher-Rossler \& Hofecker Fallahpour, 2003; Whitton, Warner, \& Appleby, 1996). Untreated postpartum depression is associated with maternal distress and childhood emotional, behavioral, and developmental problems therefore, early recognition and treatment are imperative (Righetti-Veltema, Bousquet, \& Manzano, 2003). Pediatric well-baby visits are the only consistent health care contact encountered routinely by new mothers during the first two years postpartum (Chaudron, Szilagyi, Kitzman, Wadkins, \& Cornwell, 2004; Perfetti, Clark, \& Fillmore, 2004). The pediatric health care provider, who has repeated observations of behavior changes in women and their infants, has a unique opportunity to detect postpartum depression and recommend appropriate treatment.

In view of the potential consequences, it is important to detect postpartum depression in the first year postpartum. Therefore, this research study was designed to identify depression in postpartum women during the first year after birth and compare attitudes toward help seeking in depressed and non-depressed postpartum women. Screening for postpartum depression and attitudes toward help seeking will be conducted during the well-baby visits in the pediatric setting. 


\section{Background}

Postpartum depression is a serious mood disorder that can have negative effects on motherinfant interactions after birth. A diagnosis of a major depressive disorder is made by the presence of five or more symptoms including insomnia, hypersomnia, psychomotor agitation, fatigue, changes in appetite, feelings of worthlessness or guilt, decreased concentration, and suicidality. In addition, at least one of the following symptoms, including depressed mood or loss of interest or pleasure, must be present (APA, 2000). The reported incidence of postpartum depression in the United States has ranged from 10-15\% (Beck, 2008, part 1; Ugarriza \& Robinson, 1997). Symptoms of depression have been reported by postpartum women from a few weeks after birth to two years after birth (Beck, 2008, part 1; Gaynes, Gavin, Meltzer-Brody, Lohr, Swinson, Gartlehner, Brody, \& Miller, 2005; Horowitz \& Goodman, 2004; Mayberry, Horowitz, \& Declercq, 2007; O'Hara \& Swain, 1996).

Many postpartum women do not recognize the symptoms of depression which results in an illness that goes undetected (Riecher-Rossler \& Hofecker Fallahpour, 2003; Whitton, Warner, \& Appleby, 1996). Even when these symptoms become significant and interfere with daily activities, a majority of women do not seek help for their symptoms (McGarry, Kim, Sheng, Egger, \& Baksh, 2009; Woolhouse, Brown, Krastev, Perlen, \& Gunn, 2009). There are several explanations reported by postpartum women for a delay in help seeking. These include lack of time, stigma or shame, unavailable resources, childcare issues, decreased satisfaction with health care services, and feelings that they could deal with depression on their own (Goodman, 2009; Holopainen, 2002; McCarthy \& McMahon, 2008; RiecherRossler \& Hofecker Fallahpour, 2003; Webster, Pritchard, Linnane, Roberts, Hinson, \& Starrenburg, 2001; Woolhouse, Brown, Krastev, Perlen, \& Gunn, 2009).

Postpartum depression can have devastating and long lasting effects for the mother, her infant, and her family. If left untreated, postpartum depression can have negative outcomes including maternal 
distress and infant behavioral, cognitive, emotional, and developmental problems (Beck, 2008, part 2; Dawson, Frey, Panagiotides, Yamada, Hessl, \& Osterling, 1999; Murray \& Cooper, 1997; RighettiVeltema, Bousquet, \& Manzano, 2003; Weinberg \& Tronick, 1998). Infants of depressed mothers have demonstrated insecure attachment behaviors, poorer mental and motor development, less verbal interaction, and compromised cognitive functioning.

Given the frequency of interactions with new mothers and their infants, the pediatric office provides the unique opportunity to screen and identify maternal depression. Detection and management of maternal depression at well child visits could improve maternal and infant outcomes. Feinberg, Smith, Johnson, Morales, Claussen, Smith, \& Perou (2006) developed a model of management focused on postpartum depression screening in the pediatric setting. This model includes the components of universal screening of all mothers attending well child visits, assessment of additional symptoms, educational discussions, and guidance regarding referrals.

Considering the profound impact of untreated postpartum depression on both mother and infant, early screening and treatment are imperative for healthy outcomes. The relationship with the obstetrician is usually terminated after the six week follow-up visit however; pediatric well-child visits are initiated and scheduled every two months for the first year after birth. This setting provides a feasible environment for early screening, education, and referral for treatment of postpartum depression.

\section{Significance}

Postpartum depression is the most common complication after childbirth and has significant adverse effects on women and their infants (Moses-Kolko \& Roth, 2004). Postpartum women with depression experience emotional instability, insecurity, anxiety, and feelings of worthlessness. Postpartum depression intensifies the feeling of losing control and inhibits positive maternal-infant 
interactions (Beck, 2002). Postpartum women that delay help seeking often demonstrate difficulty in differentiating between normal postpartum adjustment and depression. These women recognize that depression symptoms are out of the ordinary but were unaware that they may be experiencing postpartum depression (Holopainen, 2002; McCarthy \& McMahon, 2008). The presence of symptoms can impact the decision to seek help for an illness. Symptoms can be mild or unlikely to interfere with daily activities and therefore, neglected or ignored. Severe symptoms of an illness can be stigmatizing and result in a delay of actual help seeking (McCarthy \& McMahon, 2008). There is limited research on the impact of severity of symptoms on help seeking in postpartum women.

Individual attitudes toward help seeking influence the intent of actual help seeking behavior. Positive or negative outcome expectations influence self reported attitudes and intentions to seek help. Individuals who perceive health services negatively are less likely to access such services (Vogel \& Wester, 2003; Vogel, Wester, Wei, \& Boysen, 2005). It is important to identify the population of postpartum women that are more likely to delay help seeking. Reported reasons for delayed help seeking include stigma or embarrassment, lack of available resources, limited healthcare professional's communication skills, lack of trust, decreased quality of interaction with healthcare professional, and lack of valid knowledge of treatment options (McCarthy \& McMahon, 2008; Thome, 2003; Woolhouse, Brown, Krastev, Perlen, \& Gunn, 2009).

The impact of untreated postpartum depression is not only on the woman, but the child as well. Untreated early postpartum depression has been associated with adverse cognitive and emotional development in infants 1-2 years of age, including poorer performance on cognitive development indices and less interpersonal functioning while interacting with their mother. Infants also display less affection, less verbal interaction, and more anxiety (Murray \& Cooper, 1997; Righetti-Veltema, Bousquet, \& Manzano, 2003; Weinberg \& Tronick, 1998). Postpartum women with depression perceived their children as difficult and felt inadequately prepared to care for them (Webster, et al., 2001). Given 
the significant adverse effect of postpartum depression on women and their infants, early recognition and screening is imperative. Understanding what prevents postpartum women from help seeking for depression will improve treatment rates and overall health of childbearing women and their families.

This study will examine the incidence and severity of postpartum depression and attitudes toward help seeking among new mothers at well baby visits. Attitudes toward help seeking will be compared in postpartum women with or without depression. The incidence and severity of postpartum depression and the attitudes toward help seeking will be examined any time from birth through the first postpartum year during the well baby visits at the pediatric office.

\section{Research Questions}

1. What is the incidence and presence of depressive symptoms among postpartum women during the first year postpartum?

2. Is there a difference in help seeking attitudes between women with no depressive symptoms and those with mild or major depressive symptoms during the first postpartum year?

3. Are there differences in attitudes toward help seeking among postpartum women with depressive symptoms that seek help and those with depressive symptoms that do not seek help?

4. Is there a relationship among selected demographics, presence of depressive symptoms, and attitudes toward help seeking in postpartum women during the first postpartum year? 


\section{Chapter Two: Review of the Literature}

This chapter will introduce the theoretical framework used to guide this research and a review of the literature related to postpartum depression and help seeking in postpartum women. In each section, findings of individual studies will be presented followed by an analysis of the body of research.

\section{Theoretical Framework}

The theoretical framework that will guide this study is based on the social behavioral models that identify predictors of behavior. Ajzen (1991) developed the Theory of Planned Behavior to explain how people make the decisions to act out a certain behavior. Individuals act in accordance with their intentions and perceptions of control over the behavior, while intentions in turn are influenced by attitudes toward the behavior, subjective norms, and perceptions of behavioral control. The central factor in this theory is the individual's intention to perform a given behavior. Intentions are assumed to capture the motivational factors that influence a behavior. Intentions are indicators of how hard individuals are willing to try or plan to exert to perform the behavior. As a general rule, the stronger the intention to engage in the behavior, the more likely it is to occur (Ajzen, 1991).

Behavior is influenced by an individual's intention to perform the behavior. Intentions to perform the behavior are influenced by three antecedent conditions; perceived behavioral control, subjective norms, and attitudes toward the behavior. Perceived behavioral control is the perceived ease or difficulty of performing the behavior of interest. Perceived behavioral control varies across situations and actions. An individual's behavior is strongly influenced by their confidence in their ability to perform the behavior. The second condition, subjective norm, refers to the individual's perceived social pressure to perform or not to perform the behavior. One of the factors influencing an individual's beliefs about what others expect is the perception of the other's attitude toward the behavior of interest. The last condition is the attitude toward the behavior. This refers to the degree to which a person has a 
favorable or unfavorable evaluation or appraisal of the behavior of interest. Attitudes are formed from an individual's beliefs and values. Each belief links the behavior to a certain outcome or attribute of the behavior. Since the attribute or belief that is linked with the behavior is already valued positively or negatively, an attitude is automatically acquired toward that behavior. Individuals form favorable attitudes toward behaviors that are believed to have largely desirable consequences and unfavorable attitudes toward behaviors that are believed to have negative consequences (Ajzen, 1991).

\section{Model of Investigation}

The model of investigation that will be used to guide this study is depicted in Figure 1. The model demonstrates the steps in the decision to seek help for postpartum depression, as guided by Ajzen's theory. Help seeking is a key factor influencing detection and treatment of depression (McGarry,

Kim, Sheng, Egger, \& Baksh, 2009). Attitudes are strong predictors of actual behavior. Attitudes, already valued as positive or negative, impact the actual behavior (Ajzen, 1991). This study will use elements of the Theory of Planned Behavior to analyze the influence of attitudes toward seeking help for depression on actual help seeking in postpartum women within the first year after birth. This study will examine how the presence of depressive symptoms, demographic variables, and attitudes toward help seeking influence actual help seeking behavior. 
Figure 1. Conceptual Model of Help Seeking in Postpartum Women

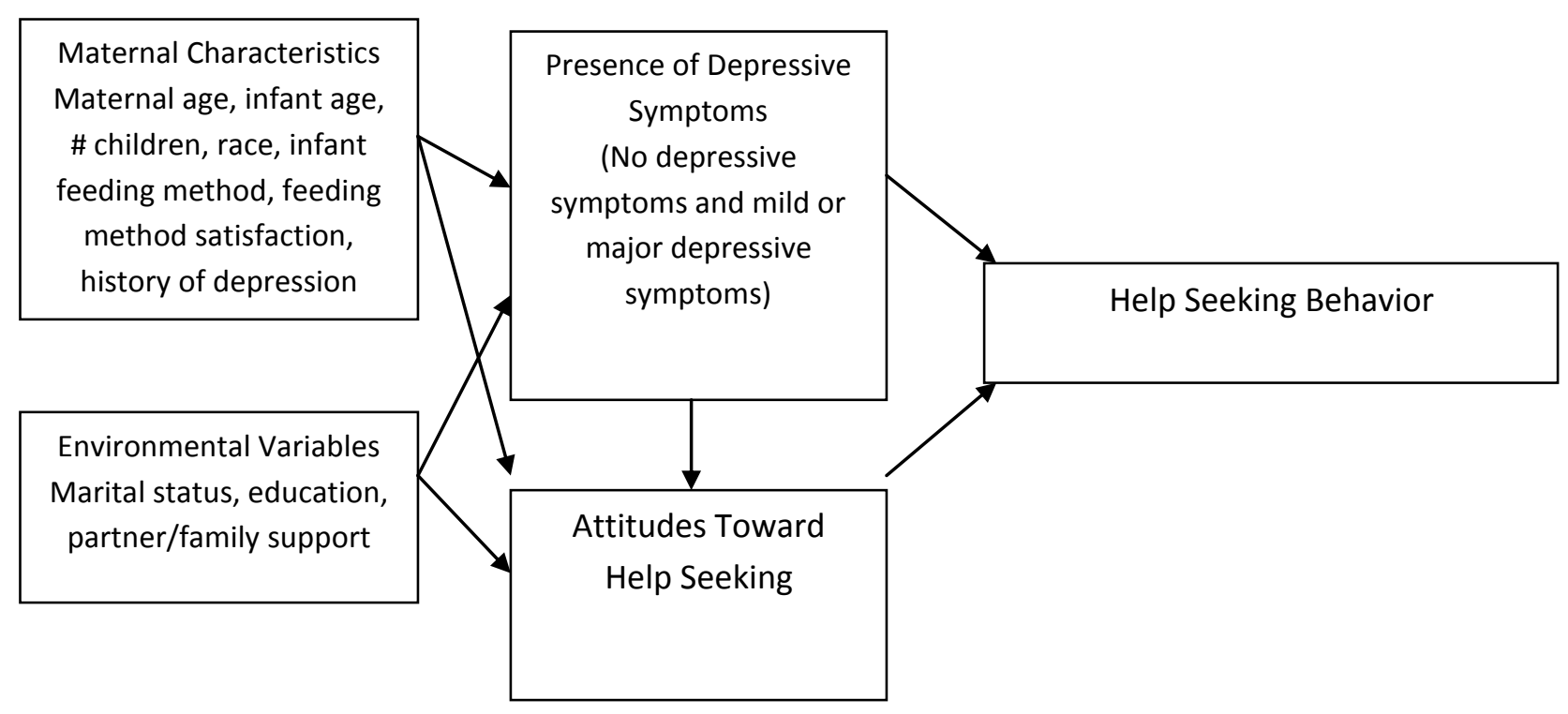

Adapted from Ajzen, I. (1991). The Theory of Planned Behavior. Organizational Behavior and Human Decision Processes, 50, 179-211. 


\section{Literature Review}

An integrated review methodology by Whittemore and Knafl (2005) was utilized to combine diverse methodologies into integrated results and conclusions. This review method analyzes each article of interest that describes the phenomena of study utilizing a framework which involves a five stage process including problem identification, literature search, data evaluation, data analysis, and presentation. Quantitative, qualitative, mixed method, meta-synthesis, meta-analysis, systematic and integrative research studies were included in this review. Meta-analysis research studies were included in this review to provide evidence of multiple primary studies and to validate these findings. Systematic reviews contributed to the review of the literature on postpartum depression incidence, prevalence, and diagnosis. Meta-synthesis research studies were included in this review to present the findings of several qualitative studies focusing on the lived experience of women with postpartum depression. Integrative review studies utilized both experimental and non-experimental research to provide further information about help seeking in women with postpartum depression (Whittemore \& Knafl, 2005).

An extensive search involved review of published peer review articles from 1970 to 2010. The key words postpartum, postpartum depression, help seeking, pediatric nurse practitioner, and pediatric setting/pediatrician were utilized for searching the databases. The databases searched included Academic Search Premier, CINAHL, MEDLINE, Mental Measurements Yearbook, PsycINFO, PsycARTICLES, and Women's Studies International. Inclusion criteria focused on research articles, integrated reviews, systematic reviews, meta-analysis reviews, and meta-synthesis reviews, in English, that were published in the last 40 years. Research articles that examined women during the first two years postpartum were included. Research articles focusing on women that experienced other psychological disorders or high risk situations, such as domestic violence, were not included. Domestic abuse has legal implications that may affect the process of help seeking and therefore, were excluded from this review. Research that focused on postpartum women with infants diagnosed with high risk conditions or disorders and studies 
focusing on foreign born postpartum women were also excluded from this review. Parents of infants with high risk conditions are focused on their infant's condition and recovery which may ultimately affect help seeking under normal postpartum conditions. There are no significant differences in depressive symptoms or help seeking rates among various cultural groups therefore, research articles focusing on one specific group of women were not considered (Beck, 2008, part 1; Huang, Wong, Ronzio, \& Yu, 2007).

The literature review is organized according to the conceptual model. The first section of the literature review includes research related to postpartum depression including the diagnosis, incidence, prevalence, risk factors, emotional response, maternal-infant impact, and screening practices. The second section of the review includes the research on help seeking measurement and attitudes.

\section{Postpartum Depression}

Diagnosis

Postpartum depression is a major depressive disorder with possible long term implications for the new mother and her infant. Diagnosis is either achieved through diagnostic criteria or self-report questionnaires. The diagnostic criteria for a major depressive disorder includes five or more symptoms including depressed mood, markedly diminished interest or pleasure in an activity, appetite disturbance, sleep disturbance, physical agitation or psychomotor retardation, fatigue, feelings of worthlessness, diminished concern or inability to make decisions, and recurrent thoughts of death or suicide (APA, 2000). The Diagnostic and Statistical Manual of Mental Disorders, fourth edition text revision (DSM-IVTR) (2000), specifies onset of postpartum depression within four weeks after birth but most clinicians agree that postpartum depression can occur up to a year after childbirth. Minor depression is impairing, yet less severe, with fewer depressive symptoms reported (Gaynes, et al., 2005). 
Several questionnaires are also utilized to screen for postpartum depression. The two most common questionnaires, developed specifically for depression screening in postpartum women, are the Edinburgh Postnatal Depression Scale (EPDS) and the Postpartum Depression Screening Scale (PDSS). The EPDS is a 10-item self-report questionnaire established for detecting symptoms of postpartum depression. Using a cutoff score of 12/13 for the EPDS, Cox and colleagues (1987) reported a sensitivity of $86 \%$, specificity of $78 \%$, and positive predictive value of $73 \%$. The alpha reliability of the EPDS was 0.87. A cutoff of $12 / 13$ is recommended for major postpartum depression and a score of 9 or more for both major and minor depression(Cox, Holden, \& Sagovsky, 1987).

The Postpartum Depression Screening Scale (PDSS) is a 35-item self-report questionnaire developed to assess seven dimensions including sleeping/eating disturbances, anxiety/insecurity, emotional lability, cognitive impairment, loss of self, guilt/shame, and contemplating harming oneself. Total scores range from 35 to 175 . Scores of 60 to 79 represent significant symptoms of postpartum depression while scores of 80 to 175 constitute a positive screen for major postpartum depression. Researchers reported an excellent internal consistency, with an alpha coefficient of 0.97 for the PDSS total score (Beck \& Gable, 2000).

Incidence and Prevalence

The incidence of major depression ranges from $1.0 \%$ to $5.9 \%$ at different times during the first postpartum year (Gaynes, et al., 2005). Combined minor and major depression incidence ranges from $6.5 \%$ to $12.9 \%$ in the same period of time (Gaynes, et al., 2005). The highest prevalence rates for major depression occur at two and six months postpartum while the highest prevalence rates for both minor and major depression occur at three months postpartum (Eberhard-Gran, Eskild, Tambs, Samuelsen, \& Opjordsmoen, 2002; Gaynes, et al., 2005; O'Hara \& Swain, 1996; Woolhouse, Brown, Krastev, Perlen, \& Gunn, 2009). A majority of the research demonstrates an overall depression rate of 
10\%-15\% (Beck, 2008, part 1; Ugarriza \& Robinson, 1997). These studies were generally of moderate size but too small for reliable analysis. Comparison among the research studies remains difficult due to a lack of consistent measures of postpartum depression and depression cutoff scores with each of the screening tools.

Depressive symptoms have been reported in women up to two years after childbirth. Approximately one half of women that experienced depressive symptoms in the early months after birth continue to experience the same symptoms at six months postpartum (Ugarriza \& Robinson, 1997). In studies that conducted long term screening in childbearing women, many women that demonstrate early depressive symptoms continue to experience these symptoms for up to two years after birth (Horowitz \& Goodman, 2004; Mayberry, Horowitz, \& Declercq, 2007). Beck (2008, part 1) reviewed the prevalence of postpartum depression symptoms in 141 postpartum depression research studies. Elevated depressive symptoms were reported at 4 to 8 weeks, 10 to 14 weeks, and 14 to 18 weeks after delivery. Overall incidence was reported as $12 \%$ to $41.9 \%$ with up to $19 \%$ of new mothers experiencing minor or major depression episode within the first three months after delivery.

Eberhard-Gran and colleagues (2002) conducted a quantitative cross-sectional descriptive study of women recruited from a community based child health clinic in Norway to determine depression prevalence among postpartum and non-postpartum women. The sample of 2577 non-postpartum women and 467 postpartum women was assessed for depression utilizing the EPDS and the Hopkins Symptom Checklist. A cutoff score of $\geq 10$ was used to detect depression in the EPDS. The prevalence of depression was $8.9 \%$ in the postpartum group and $13.6 \%$ in the non-postpartum group (Eberhard-Gran, Eskild, Tambs, Samuelsen, \& Opjordsmoen, 2002). A similar study of women recruited from a postpartum unit in a large hospital in Southeastern Massachusetts was conducted to determine prevalence of postpartum depression symptoms over the period of time from birth to two years postpartum (Horowitz \& Goodman, 2004). Of the 1,215 women who completed the EPDS at 2-4 weeks 
postpartum, 123 women had elevated scores and agreed to participate in the study. The Beck Depression Inventory II was used to measure presence and severity of depression at 4-8 weeks, 10-14 weeks, $14-18$ weeks and again at two years after birth. At time one, $4-8$ weeks postpartum, $41.9 \%$ of women scored positive for depression. At two years after delivery, $30.6 \%$ of participants continued to have BDI-II scores in the depressed range. A lack of a significant decrease in depression scores from 4-8 weeks postpartum to two years after birth indicates that symptoms persisted for many women (Horowitz \& Goodman, 2004).

O'Hara and Swain (1996) conducted a meta-analysis of the rates and diagnosis of postpartum depression. Overall prevalence of postpartum depression, based on estimates from 59 studies, was 0.13 ( $n=12,810 ; \mathrm{Cl}: 0.123 / 0.134)$. Prevalence estimates were affected by the nature of the assessment method and by the length of the postpartum period under evaluation. Self report questionnaires yielded significantly higher estimates of postpartum depression than interview based methods, self-report $(n=$ 28 studies): 0.14, 95\% Cl: 0.131/0.149; interview ( $\mathrm{n}=31$ studies): $0.12,95 \% \mathrm{Cl}: 0.113 / 0.127 ; \mathrm{t}(57)=$ $2.08, p<0.05$. Studies which utilized a wider period of time to estimate prevalence of depression usually reported higher prevalence rates than studies that used a narrower period of time. The number of days postpartum when the depression assessment was completed and the nation in which the study was conducted did not significantly predict prevalence estimates (O'Hara \& Swain, 1996).

\section{Risk Factors}

Several risk factors have been associated with postpartum depression. Maternal age, parity, infant feeding method, history of depression, marital satisfaction, educational level, social support, income and life stressors are the most common socio-demographic variables that are reported in the literature (Beck, 2008, part 1; Dennis \& Chung-Lee, 2006; Eberhard-Gran, Eskild, Tambs, Samuelsen, \& Opjordsmoen, 2002; Horowitz \& Goodman, 2004; Howell, Mora, Horowitz, \& Leventhal, 2005; 
Mayberry, Horowitz, \& Declercq, 2007; O'Hara \& Swain, 1996).O'Hara \& Swain (1996) determined that family income and mother's occupation were small, but significant predictors of postpartum depression. Higher level of obstetrical complications were weakly associated with postpartum depression and moderately associated with higher levels of self-reported depressive symptoms. Life events prior to the birth of the child and support from the infant's father were also significant predictors of postpartum depression (O'Hara \& Swain, 1996).

Boyce \& Hickey (2005) conducted a study on 425 postpartum women recruited from a public hospital in Australia. The percentage of women with depression as defined by the EPDS, with a score of more than 12 , was $8.9 \%$ at six weeks postpartum. Women age 16 or younger were significantly more likely to be identified as having postpartum depression ( $\mathrm{OR}=14.65,95 \% \mathrm{Cl} 2.38-90.38)$. Women that identified themselves as unemployed or on an employment benefit had an increased risk of postpartum depression $(\mathrm{OR}=2.74,95 \% \mathrm{Cl}$ 0.92-7.81). There were no reported differences in years of education, marital status, or partner support (Boyce \& Hickey, 2005). A similar study of 594 mothers in British Columbia investigated risk factors associated with postpartum depression at one week postpartum. Several demographic variables were predictive of postpartum depression. Past history of depression (OR $=4.94,95 \% \mathrm{Cl} 1.05-3.16)$, life events $(\mathrm{OR}=1.12,95 \% \mathrm{Cl} 1.01-1.24)$, perceived partner support $(\mathrm{OR}=$ $0.97,95 \% \mathrm{Cl} 0.96-0.98)$, and dissatisfaction with feeding method ( $\mathrm{OR}=2.47,95 \% \mathrm{Cl} 0.82-7.49)$ were significant predictors of women with scores $>9$ on the EPDS indicating depression symptoms (Dennis, Janssen, \& Singer, 2004).

A large study of 2577 non-postpartum women and 467 postpartum women, recruited from community based child health clinics in Norway, was conducted to identify risk factors associated with postpartum depression. Among the $8.9 \%$ of postpartum women with positive depression scores of $\geq 10$ on the EPDS, several risk factors were associated with depression. Non-breastfeeding women were significantly more depressed than breastfeeding women ( $\mathrm{OR}=12.4,95 \% \mathrm{Cl} 1.7-89.7)$. Increase in life 
events $(\mathrm{OR}=6.6,95 \% \mathrm{Cl} 1.7-25.6)$, prior depression $(\mathrm{OR}=5.3,95 \% \mathrm{Cl} 1.9-14.7)$, and parity of one child $(\mathrm{OR}=3.1,95 \% \mathrm{Cl} 1.2-9.1)$ were significantly associated with depression in the postpartum and nonpostpartum group (Eberhard-Gran, Eskild, Tambs, Samuelsen, \& Opjordsmoen, 2002). Horowitz \& Goodman (2004) also identified several contributing factors to postpartum depression. The Beck Depression Inventory-II (BDI-II) was utilized to measure presence and severity of depression symptoms from $4-8$ weeks postpartum to 2 years postpartum. First time mothers $(.400, p=.001)$, low income $(-.413, p=.001)$, positive depression history $(.381, p=.002)$, decreased overall support $(-.401, p=.001)$, and high parental stress $(.425, p=.001)$ were significantly correlated to positive depression scores at 2 years postpartum (Horowitz \& Goodman, 2004).

In a cross-sectional sample of 1,359 American women in the first 2 years postpartum, differences in depression symptom rates and factors associated with depression were examined. In terms of age, the highest rates of both mild (16.4\%) and moderate to severe (29.9\%) EPDS depression scores were among the youngest mothers (18-24 year olds) in the total sample. Women in the lowest income bracket also had the highest rates with almost half having scores reflecting either mild (18.9\%) or moderate to severe (31.0\%) depression symptoms. Women with educational completion of high school or less had the highest moderate to severe depression symptom rate $(27.5 \%)$ as compared to women with some college (16.5\%) and college graduates $(9.3 \%)$ with a much lower rate. Women with the highest rate of moderate to severe depression scores were those with two children (22.1\%). Race was not associated with depression symptom rates. Very small differences were reported between women classified as either white or non-white ((Mayberry, Horowitz, \& Declercq, 2007).

\section{Emotional Response}

Women with postpartum depression experience an intense emotional response described as an overwhelming feeling of doom. In a meta-synthesis of 18 qualitative studies on postpartum depression, 
four themes emerged from the description of women's lived experience of postpartum depression. These include incongruence between expectations and reality, spiraling downward, pervasive loss, and making gains. Incongruence involves the difference between the visions of what motherhood would be like and the actual responsibilities and adaptations required of the new mother. As women describe their experiences, it becomes clear that many factors contribute to the difference in their expectations and the reality of motherhood. Spiraling downward is reported as an overwhelming or worsening of depressive symptoms. Pervasive loss is the loss of control or loss of self that is encountered during the postpartum period. Making gains, or getting to the other side, is a form of surrendering or recognizing that something is wrong and help is needed (Beck, 2002).

Similar findings were reported in a qualitative study of eight women who had recovered from postpartum depression. Three stages evolved in the discussion of their experiences. The first stage, "why did this happen," represents an attempt by these women to understand or determine a reason for their depression. Women described the need to make sense of why they have experienced postpartum depression and determine the factors that may have contributed to their depression. Problematic relationships, significant life changes, and ambivalence about the pregnancy were factors that were discussed as possible reasons. "Spiraling downward" focuses on the actual experience of postpartum depression. During this stage women described a shift in adjustments associated with motherhood to a loss of self and identity. These women with postpartum depression felt as though they were losing control and becoming isolated with those around them. They often experienced insomnia, inability to make decisions, and thoughts of hurting the baby and self. The third stage, "getting to the other side," involved recognizing that something was significantly affecting every aspect of their lives. Women sought help at different stages of their depression. Although they reported relief and hope, stigma was also a great concern (Berggren-Clive, 1998). 


\section{Maternal-Infant Impact}

Several studies describe the negative impact of postpartum depression on maternal-infant interactions and infant development. Play, attachment behaviors, behavioral problems, cognitive development and emotional development were addressed in these studies. Murray and Cooper (1997) presented a review of seven research studies focused on the effects of postpartum depression on infant development. Infants of mothers with postpartum depression were significantly more likely to fail on Piaget's object permanence task, a key measure of the infant's capacity for mental representation; and on the Bayley scales of mental development. Several studies reported a significant association between insecure attachment behaviors and high levels of maternal depression in 12-18 month old infants. Women that experienced postpartum depression were more likely to report behavioral difficulties, including sleeping and eating problems, temper tantrums, and separation difficulties, in their children at 18 months of age (Murray \& Cooper, 1997).

Beck (2008, part 2) summarized 141 postpartum depression studies conducted by nurse researchers all over the world. Several studies examined the long term impact of postpartum depression on mother-child interactions. Fifteen to eighteen month old children of mothers who had elevated depressive symptoms at 2 months after delivery displayed less persistence in play and less joy in reunion after separation from their mothers than children of non-depressed mothers. Righetti-Veltema, Bousquet, \& Manzano (2003) examined the impact of postpartum depression on a community sample of 35 mothers and their 18 month old infants. The Guaraldi test and the Bur scale were utilized to assess maternal-infant relationships. Several measures of infant development were utilized including the Denver Developmental Screening Test (DDST), the Bayley Scales of Infant Development, and observation of infant attachment and object concept tasks. Infants of depressed mothers demonstrated little verbal interaction (22.9\%) as compared to infants of non-depressed mothers (0\%) as assessed by the Bur Scale $(p<0.05)$. Infants of mothers who presented with depressive symptoms searched much less for their 
mother during the separation episodes than the infants of mothers who were not depressed. The infants of mothers with postpartum depression vocalized and smiled less at mother; mothers with PPD were less affectionate, less cooperative, and less responsive to their infants. The infant's performance on the object concept task was significantly linked with postpartum depression. Only $42.9 \%$ of the infants of mothers with PPD achieved the level corresponding to their age, whereas $77.1 \%$ of the infants of non-depressed mothers achieved this level $(p=0.0059)$. No significant correlation was found between these results and infant gender (Righetti-Veltema, Bousquet, \& Manzano, 2003).

Depressed mothers are sufficiently different from non-depressed mothers in affect and interaction with their infants. Weinberg and Tronick (1998) examined emotional characteristics of infants to 30 depressed mothers, undergoing treatment, recruited from a child development unit at a large Boston Children's Hospital and 30 non-depressed mothers recruited from the community. Mothers and their infants were videotaped during interaction and play at 3 months postpartum. Compared with control subjects, mothers in the treated depression group talked less to their infants, touched their infants less, and were less likely to share their infants' focus of interest. Infants of the mothers receiving treatment for depression reacted differently to the interaction and the stranger than did infants of control mothers. They were less interested, expressed more anger and sadness, and tended to fuss and cry more (Weinberg \& Tronick, 1998). Brain electrical activity was recorded from 13-15 month old infants of depressed $(n=59)$ versus non-depressed $(n=40)$ mothers during a baseline condition and during several social conditions that included a playful social interaction. Infants of depressed mothers exhibited reduced relative left frontal brain activity in a baseline condition and in two conditions involving playful interactions, one with the mother and one with a familiar experimenter (Dawson, et al., 1999). 


\section{Screening Practices}

Screening women for postpartum depression is a challenge in the weeks after childbirth. Immediately after birth, hospital screening is often too early to make a diagnosis. The postpartum visit with the obstetrician, at six weeks, is an opportunity for screening for depressive symptoms and is an appointment focused on the woman's well being. The interaction with the obstetrician is often terminated after this follow-up visit. The new mother encounters the pediatric health care professional at least eight times in her infant's first two years of life. Screening can be easily implemented in this setting (Perfetti, Clark, \& Fillmore, 2004).

Screening for depression in the pediatric setting has been reported in the literature as reliable and feasible. In a study of 110 infants, detection was compared before and after universal screening of postpartum women. A statistically significant difference was reported between the before group (1.6\%) and the after group $(8.5 \%)$ in detecting postpartum depression $(p<.001)$. The screening tool was completed in a timely manner, easy to score, and accurate in detecting depression (Chaudron, Szilagyi, Kitzman, Wadkins, \& Cornwell, 2004). In a similar study of 96 postpartum women at their infant's eight week well-baby visit, $14.6 \%$ of women were screened as having depression. The screening in this pediatric setting was feasible and relatively well accepted by postpartum women (Freeman, Wright, Watchman, Wahl, Sisk, Fraleigh, \& Weibrecht, 2005). In both research studies, the Edinburgh Postnatal Depression Scale (EPDS) was utilized to screen for depression. The EPDS is a 10 item, self-administered questionnaire. Each item is scored from 0-3 with possible total scores of 0-30. It is recommended that scores $\geq 13$ identify women with a major depressive episode that require further assessment (Cox, Holden, and Sagovsky, 1987).

Despite the significant negative impact of untreated postpartum depression, many physicians fail to diagnose and treat maternal depression. A study of 232 physicians, including obstetricians, 
pediatricians, and family practice practitioners, reported on self administered surveys regarding their knowledge, beliefs, and perceived barriers toward managing postpartum depression. Over $90 \%$ reported that it was their responsibility to recognize postpartum depression but a large number of physicians rarely $(40 \%)$ or never $(66 \%)$ assessed for depression or provided a referral (Leiferman, Dauber, Heisler, \& Paulson, 2008). Two research studies examined the beliefs and practices of pediatricians relative to screening for maternal depression. A national survey of randomly selected pediatricians yielded 508 completed surveys. Of these pediatricians, over half (57\%) felt responsible for recognizing maternal depression. When depression was suspected, $48 \%$ completed additional assessment. Pediatricians indicated that they had an active role in $66 \%$ of the cases in which they provided one or more brief interventions. The major barriers that limited diagnosis and management were reported as insufficient time for adequate history, insufficient training on diagnosis and treatment, and lack of education or counseling (Olson, Kemper, Kelleher, Hammond, Zuckerman, \& Dietrich, 2002). Similar findings were reported in a study of 389 randomly selected pediatricians that participated in a nationwide survey to assess pediatrician knowledge and views about postpartum depression. About half of the pediatricians surveyed reported little to no education about postpartum depression and few pediatricians felt confident in recognizing maternal depression (Wiley, Burke, Gill, \& Law, 2004).

In a study of family nurse practitioners and screening practices for postpartum depression, less than half (42\%) ever screened for postpartum depression in some manner. Nurse practitioners that were knowledgeable of the symptoms and management of postpartum depression performed some formal or informal type of screening. A majority of nurse practitioners followed clinical practice guidelines of care however, there are no specific guidelines that address postpartum depression (Goldsmith, 2007).

In a systematic review of the literature on the effectiveness of postpartum support to improve maternal outcomes, it was reported that educational visits in the pediatric office setting demonstrated 
statistically significant improvements in parenting skills in low risk women. In women at high risk for postpartum depression, home visitation or peer support produced a statistically significant reduction on depression scale scores. Maternal satisfaction was higher with the home visitation programs that were identified in these studies (Shaw, Levitt, Wong, \& Kaczorowski, 2006). Feinberg, Smith, Morales, Claussen, Smith, and Perou (2006) discuss the role of pediatric providers in improving women's health through detection and management of maternal depression. The Pediatric-Based Maternal Depression Detection and Management System was developed as a three year project to highlight the feasibility of an evidence based approach to the detection and management of postpartum depression in a pediatric setting. The system components include universal screening at well-child visits, assessment of additional symptoms, an educational discussion about postpartum depression, and guidance regarding referrals. The model was developed for future research (Feinberg, Smith, Morales, Claussen, Smith, \& Perou, 2006).

\section{Help Seeking}

Help seeking is defined as the process of initiating an interaction with another individual to obtain support, information, advice, assistance, or treatment (Broadhurst, 2003; Gourash, 1978). Women with postpartum depression demonstrate low rates of help seeking (McGarry, Kim, Sheng, Egger, \& Baksh, 2009; Riecher-Rossler \& Hofecker Fallahpour, 2003; Whitton, Warner, \& Appleby, 1996). While the studies on help seeking for depression in postpartum women are limited, research in the adult population with depression demonstrates similar results (Glover, Novakovic, \& Hunter, 2003; Jesse, 2008; Roness, Mykletun, \& Dahl, 2005; Vogel, Wade, Wester, Larson, \& Hackler, 2007; Wang, Patten, Williams, Currie, Beck, Maxwell, \& El-Guebaly, 2005). The literature supports the concern that women who may need help for postpartum depression often do not seek help from available resources (Broadhurst, 2003). 


\section{Measurement}

Help seeking has been measured utilizing a variety of methods. A majority of the research studies simply question the participants regarding help seeking behavior (Barney, Griffiths, Jorm, \& Christensen, 2006; Jesse, 2008; Roness, Mykletun, \& Dahl, 2005; Thompson, Hunt, \& Issakidis, 2004; Vogel, Wade, Wester, Larson, \& Hackler, 2007). This method is also commonly utilized in the help seeking research in the population of postpartum women with depression. In most of the research on adult populations with depression, help seeking intentions, attitudes, and willingness are often analyzed as a predictor of actual help seeking.

Several tools have been utilized to measure help seeking attitudes, intentions, and willingness. The General Help Seeking Questionnaire (GHSQ) was developed to formally assess help seeking intention for a range of problems. Participants are asked to rate the likelihood they would seek help from a variety of people for emotional, anxiety/depression, or suicidal thoughts. Higher scores indicate willingness to seek help. The GHSQ has been utilized in college student and adult male participants (Ciarrochi \& Deane, 2001; Cusack, Deane, Wilson, \& Ciarrochi, 2006; Smith, Tran, \& Thompson, 2008; Wilson, Deane, \& Ciarrochi, 2005).

The Patterns of Help Seeking Scale (PHSS) was developed to evaluate a participant's comfort level talking about various types of problems and willingness to seek help for those problems from various sources. Participants are presented with a short scenario describing a substance abuse or depression problem and are asked to imagine that they are experiencing that problem. The participant is also asked to select a potential source of help seeking from a list of nine potential sources. This questionnaire was also developed for use in adult men with depression or substance abuse problems (Lane \& Addis, 2005). 
The Willingness to Seek Help Questionnaire (WSHQ) is a 25 item self report questionnaire that evaluates one's openness to seek professional psychological help. Higher scores indicate greater willingness to seek help. This measure is based on the view that willingness of a person to seek help is dependent on three elements: recognition of the need for outside help, readiness for self-disclosure, and willingness to relinquish some degree of control. Positive attitudes measured by the scale resulted in actual help seeking behavior in a majority of participants. There are few studies that utilize this tool as a measure of willingness to seek professional help (Cohen, 1999; Segal, Coolidge, Mincic, \& O'Riley, 2005).

The tool that is utilized in a majority of research studies is the Attitudes Toward Seeking Professional Psychological Help (ATSPPH) Scale (Fischer \& Turner, 1970). The ATSPPH is a 29 item scale that assesses individual attitudes toward seeking professional psychological help. The tool measures four factors including the need for psychological help, stigma tolerance, interpersonal openness, and confidence in mental health practitioners. Fischer and Farina (1995) developed a 10 item one dimensional version of the original tool. The shortened form is easier and less obtrusive for use in research on attitudes toward help seeking. The shortened form has been utilized in several research studies on college student populations (Fischer \& Farina, 1995; Halter, 2004; Vogel, Wester, Wei, \& Boysen, 2005).

\section{Attitudes Toward Help Seeking}

Individual attitudes and willingness toward help seeking influence the intent of actual help seeking behavior. Individuals who perceive health services negatively are less likely to access such services. To understand why some individuals choose to seek help or not, examination of help seeking attitudes must be completed (Vogel \& Wester, 2003; Vogel, Wester, Wei, \& Boysen, 2005). Attitudes toward help seeking have been analyzed in postpartum women with depression however; no tool has 
been utilized to measure attitudes or intentions. Overall, a majority of adults fail to seek help for depression due to a variety of reasons. The barriers to help seeking include lack of trust, stigma or embarrassment, dissatisfaction of healthcare services, lack of recognition of symptoms, lack of knowledge regarding resources or treatment options, desire to cope alone, or negative attitudes and outcome expectations (Barney, Griffiths, Jorm, \& Christensen, 2006; Jesse, 2008; Outram, Murphy, \& Cockburn, 2004; Thompson, Hunt, \& Issakidis, 2004). Women with postpartum depression report many of the same barriers that result in a delay or unwillingness to seek help or treatment (McGarry, Kim, Sheng, Egger, \& Baksh, 2009; Riecher-Rossler \& Hofecker Fallahpour, 2003; Whitton, Warner, \& Appleby, 1996)

A majority of the literature on help seeking addresses problem identification as a major factor in help seeking delays. In a convenience sample of 78 postpartum women, scoring positive for postpartum depression, $76(97 \%)$ reported that they had been feeling worse than usual but only $25(32 \%)$ believed they were suffering from postpartum depression at 6-8 weeks postpartum. These women had difficulties in distinguishing between normal postpartum adjustment and impairment in their ability to function. Only 9 (12\%) of these women had spoken to a health care professional (Whitton, Warner, \& Appleby, 1996). These findings are consistent with the literature demonstrating low rates of help seeking in the population of postpartum women. In a qualitative study of fifteen mothers, diagnosed with depression and receiving treatment, women reported a reluctance to identify themselves as having postpartum depression. Many of these women revealed a perceived stigma associated with depression. Depression was viewed as a failure in the transition to new mother (McCarthy \& McMahon, 2008). Postpartum women do not recognize or understand the symptoms they are experiencing. Most women are unable to differentiate between normal transitions to motherhood and postpartum depressive symptoms (McCarthy \& McMahon, 2008; McGarry, Kim, Sheng, Egger, \& Baksh, 2009; Riecher-Rossler \& Hofecker Fallahpour, 2003; Whitton, Warner, \& Appleby, 1996). 
Women who did recognize the symptoms of postpartum depression were not aware of the available resources for help. When postpartum depressive symptoms reached a crisis level, women sought help from several sources. In a qualitative study of seven postpartum women, the most common source of help reported was the support network of the spouse or partner, family, and friends. Some women discussed their symptoms with maternal health nurses. Some women perceived their help seeking as supportive and some did not but a majority of women were referred to a psychiatrist by the health care nurses. Women were dissatisfied with hospital doctors and general practitioners claiming that they had limited time and compassion (Holopainen, 2002). In a large study of 574 postpartum women, health care use and satisfaction was compared between depressed and non-depressed women. Twenty one percent of the women were identified as depressed. Only one-half of those who scored high for depression stated depression as the reason for their visit to a health care professional. Depressed women were more likely to seek help with a psychiatrist, social worker, depression group, pediatrician, or general practitioner than non-depressed women. Overall, depressed women utilized healthcare services more frequently and were less satisfied with health professional services than non-depressed women (Webster, et al., 2001).

Many studies addressed the reasons that postpartum women did not seek help for depression. In a comprehensive review of the literature, Riecher-Rossler and Hofecker Fallahpour (2003) reported reasons for treatment delay including shame or stigma, fear of separation from infant, lack of knowledge regarding treatment, and misinterpretation of symptoms. Healthcare services often failed to meet the needs of newly postpartum women and did not consider specific situations, perceptions, problems, and fears of these women. McCarthy \& McMahon (2008) conducted a qualitative study to investigate the experience and treatment of postpartum depression in a community mental health setting. A majority of these women reported feelings of being a "bad mother," shame and guilt, and an inability to cope with motherhood as reasons in delaying help seeking. Similar findings were cited in a 
study with a convenience sample of 509 pregnant women in their last trimester of pregnancy. A majority of women (92\%) reported that they would participate in therapy if needed but only $35 \%$ would likely take medication and $14 \%$ would participate in group therapy. These women were not screened for depression, only their perceptions and attitudes toward treatment of depression. The greatest perceived barriers to help seeking were reported as lack of time, stigma, and fear (Goodman, 2009).

\section{Analysis of Research Findings}

The strengths of the studies on incidence and prevalence of postpartum depression include strong reliability and validity of the screening tools utilized to screen for postpartum depression. There are inconsistent cutoff scores for the EPDS with some studies using scores $>9$ to define a positive screen for depression while others use a cutoff score of between 10-12. These inconsistent cutoff scores make it difficult to compare results across several research studies. The methods for screening are well documented for use in this population of women. There are also well documented studies in various ethnic and minority populations for each of these screening tools. There are limited longitudinal studies that address prevalence rates of depression at various postpartum periods.

A majority of the research studies on postpartum depression are limited to a convenience sample in a specific geographical area. There are few research studies that examine help seeking in postpartum women. Finally, there are numerous studies that examine attitudes, intentions, and willingness of help seeking but few studies on the influence of attitudes on actual help seeking behavior.

As the literature suggests, screening for postpartum depression, utilizing a standardized screening tool, is rarely accomplished in any health care setting after birth. There is also a lack of knowledge among health care providers related to the screening tools, diagnosis and treatment of postpartum depression. A majority of pediatricians believe that it is their responsibility to recognize postpartum depression however; most do not screen, diagnose or treat women experiencing 
postpartum depression. There is also a lack of clinical practice guidelines for advanced nurse practitioners regarding postpartum depression assessment, diagnosis and treatment. 


\section{Chapter Three: Methodology}

\section{Purpose}

The primary purpose of this explanatory descriptive study was to examine the relationship between attitudes toward help seeking and actual help seeking in postpartum women with and without depressive symptoms. In addition, this study examined the differences in help seeking attitudes in postpartum women with no depressive symptoms and women with mild or major depressive symptoms. The research questions answered were:

1. What is the incidence and presence of depressive symptoms among postpartum women during the first year postpartum?

2. Is there a difference in help seeking attitudes between women with no depressive symptoms and women with mild or major depressive symptoms during the first postpartum year?

3. Are there differences in attitudes toward help seeking among postpartum women with depressive symptoms that seek help and those with depressive symptoms that do not seek help?

4. Is there a relationship among selected demographics, presence of depressive symptoms, and attitudes toward help seeking in postpartum women during the first year postpartum year?

Specifically, the aims of this study were to:

1. Identify the incidence and presence of postpartum depressive symptoms among new mothers in the first year postpartum. 
2. Examine differences in attitudes toward help seeking in postpartum women with no depressive symptoms and postpartum women with mild or major depressive symptoms.

3. Examine differences in attitudes toward help seeking among postpartum women with depressive symptoms that seek help and those that do not seek help.

4. Describe the relationship among selected socio-demographic factors (maternal age, infant age, race/ethnic group, number of children, infant feeding method, satisfaction with feeding method, marital status, history of depression, educational level, and partner/family support), presence of depressive symptoms, and attitudes toward help seeking.

\section{Sample}

This study utilized a convenience sample of 130 postpartum women from northwestern Pennsylvania who agreed to participate in the study. Postpartum women were recruited from a busy pediatric practice setting in the same area. A power analysis was conducted to determine the necessary sample size. To detect a medium effect with an alpha $=0.05$ and power $=0.80$, a total of 128 subjects were required with at least 64 women in the no depressive symptom group and 64 women in the mild or major depressive symptom group (Munro, 2005). Inclusion criteria were maternal age greater than 18 years, infant age of 0-12 months of age, healthy infant without high risk acute or chronic conditions present, and ability to read and comprehend English. Postpartum women under the age of 18 years, with infants over 1 year of age, or with infants that have high risk acute or chronic conditions were excluded from this study. 


\section{Variables}

\section{Postpartum Depression}

Postpartum depression is a major depressive disorder. The diagnostic criteria for a major depressive disorder includes five or more symptoms including depressed mood, markedly diminished interest or pleasure in an activity, appetite disturbance, sleep disturbance, physical agitation, or psychomotor retardation, fatigue, feelings of worthlessness, diminished concern or inability to make decisions, and recurrent thoughts of death or suicide (APA, 2000). Minor depression is impairing, yet less severe, with fewer depressive symptoms reported (Gaynes, et al., 2005). Postpartum depressive symptoms were measured using the Postpartum Depression Screening Scale (Beck \& Gable, 2000). The Postpartum Depression Screening Scale (PDSS) was developed to assess the presence, severity, and type of postpartum depression symptoms. The PDSS is a 35-item self-report instrument that can be completed by the participant in about 5-10 minutes. The measure yields the total score, which determines the overall severity of postpartum depressive symptoms and indicates whether the woman needs to be referred for additional diagnostic evaluation. The PDSS items are easy to read and comprehend for anyone with third grade or better reading skills. The items consist of statements about how a mother may be feeling after the birth of her baby. The items employ a Likert-type, 5 point response format ( 1 = strongly disagree; 5 = strongly agree). Higher scores on the PDSS indicate higher levels of postpartum depression symptomatology, while lower scores indicate fewer symptoms and suggest a relatively normal postpartum adjustment.

The PDSS provides content scales for the following seven symptoms areas: sleeping/eating disturbances, anxiety/insecurity, emotional lability, mental confusion, loss of self, guilt/shame, and suicidal thoughts. The PDSS can yield separate scores for each of the seven scales however, for this study only the total score was utilized to distinguish between no depressive symptoms, mild depressive 
symptoms, and major depressive symptoms. Total scores on the PDSS can range from 35 to 175 . Scores in the range of 35-59 are interpreted as representing normal adjustment or lack of significant symptoms of postpartum depression. Women who score in this range generally do not need to be referred for psychiatric evaluation. Scores in the range of 60-79 represent significant symptoms of postpartum depression. Many, though not all, of the women scoring in this range are in need of formal psychiatric evaluation. Scores in the range of 80-175 constitute a positive screen for major postpartum depression. Although this is not equivalent to diagnostic criteria for major depression, it does indicate a high probability that the woman has this disorder. Women with scores is this range are in definite need of psychiatric evaluation (Beck \& Gable, 2000).

The psychometric properties of this tool are well documented. Internal consistency reliability for the PDSS total score yielded an alpha coefficient of 0.97 and coefficients ranging from 0.83 to 0.94 for the seven symptoms content scales. The content validity of the PDSS was established by means of two expert rater studies, where experts in postpartum depression rated the extent to which the PDSS pilot items correctly described the symptom content of this disorder. The criterion validity of the PDSS was established in relation to several criterion measures, including a structured diagnostic interview and two other self-report depression inventories. Convergent validity of the PDSS was established through correlations from two other self-report depression inventories (The Edinburgh Postnatal Depression Scale and the Beck Depression Inventory-II) and depression diagnostic status as derived from the Structured Clinical Interview for DSM-IV. The PDSS total score was strongly correlated with the Edinburgh Postnatal Depression Score (EPDS) score $(r=0.79, p<.0001)$, the Beck Depression InventoryII (BDI-II) score $(r=0.81, p<.00001)$, and the Structured Clinical Interview for DSM-IV (SCID) diagnostic status $(r=0.70, p<.0001)$. 
The pilot version of the PDSS was administered to 525 women recruited from eight different sites on the East Coast and in the Midwest. The dimension level reliabilities ranged from 0.83 to 0.94 indicating that all items have fairly high correlations with their targeted dimensions. Confirmatory analysis provided empirical support for the existence of the hypothesized seven dimensions. A TuckerLewis goodness-of-fit index of 0.87 and a root mean square residual of 0.05 were judged supportive of model fit (Beck \& Gable, 2000). Hanna, Jarman, \& Savage (2004) evaluated the clinical application of the PDSS and the EPDS on a sample of 84 women at eight weeks postpartum. The alpha internal consistency reliability scores for the PDSS scales ranged from 0.83 to 0.93 . The PDSS total scores ranged from 35143 , with a mean of $54.94(S D=24.69)$. Over half of the women $(n=57,73 \%)$ scored between 35 and 59 , a range classified as representing normal postpartum adjustment. Seventeen percent $(n=13)$ of the women had scores ranging from 60-79, a range classified as representing significant symptoms of postpartum depression. Ten percent $(n=8)$ scored between 80 and 175, a range classified as representing a positive screen for major postpartum depression. There was a statistically significant correlation between total scores obtained on the PDSS and total scores obtained on the EPDS $(r=0.827$, $p=0.001)$. All of the eight women who were classified by the PDSS as having a positive screen for depression also scored above the cut-off range on the EPDS (Hanna, Jarman, \& Savage, 2004). The PDSS was purchased through Western Psychological Services (www.wpspublish.com).

\section{Help Seeking}

Help seeking is the process of initiating an interaction with another individual to obtain support, information, advice, assistance, or treatment (Gourash, 1978). Attitudes toward help seeking and actual help seeking were measured in this study. Attitudes toward help seeking were measured using the Attitudes Toward Seeking Professional Psychological Help Shortened Form (ATSPPH-SF). The ATSPPH-SF was developed from the Fischer and Turner (1970) 29 item original scale for measuring attitudes toward 
seeking psychological help. The shortened, 10 item uni-dimensional version was developed by Fischer and Farina (1995). The ATSPPH-SF was administered to 389 students enrolled in an introductory psychology course at the University of Connecticut. Approximately half $(n=154,40 \%)$ indicated that they had previously experienced a serious emotional or personal problem. Of these students, $52 \%$ ( $n=$ 42) had sought professional help for the problem. The point bi-serial correlation between having sought help or not and the person's scale score was $0.39(p<.00001)$ overall. The correlation between scores from the new and the old versions of the scale was $0.87(N=62)$.

The ATSPPH-SF has been utilized on various populations of psychology and nursing students to determine the relationship between attitudes toward help seeking and actual help seeking behavior (Halter, 2004; Vogel, Wester, Wei, \& Boysen, 2005). The tool has not been used with postpartum women so a pilot study was conducted in January of 2010 to evaluate the use of this tool on the population of postpartum women. The ATSPPH-SF was administered to 10 postpartum women between 2 and 6 months postpartum at a pediatric practice in Northwestern Pennsylvania. Women recruited for the study were 18 years of age or older, spoke and understood English, and had healthy infants. All questionnaires were completed anonymously and input regarding the questionnaire was shared with the researcher after completion. All ten women believed that the tool was easy to complete and measured attitudes toward help seeking. All ten of the women completed the questionnaire in less than 10 minutes before or after their well baby visit to the pediatrician. Four of the women (40\%) suggested a more current term to replace "mental breakdown" in item one. The original item states "If I believed I was having a mental breakdown, my first inclination would be to get professional attention." Two of the women suggested "severe depression" as a more current alternative. Permission to change the terminology and use the tool was obtained by Dr. Edward H. Fischer. 
Actual help seeking was measured by a statement on the demographic sheet. All participants were asked for a yes or no response to indicate if they sought professional help or made an appointment for professional help since the birth of their baby. Differences in attitudes toward help seeking were compared in women with depressive symptoms that sought help and those that did not seek help. The influence of attitudes toward help seeking on actual help seeking was determined in the sample of women that had depressive symptoms.

\section{Socio-demographic Variables}

All socio-demographic data were collected by self-report on a demographic information sheet. These data included maternal age, infant age, number of children, race/ethnic group, infant feeding method, satisfaction with feeding method, marital status, history of depression, educational level, and partner/family support. These variables appeared most frequently in research examining postpartum depression and help seeking in new mothers. A relationship was determined among each of these sociodemographic variables, presence of depressive symptoms and the attitudes toward help seeking.

\section{Maternal age}

Maternal age has been correlated with postpartum depression in a few research studies. Postpartum women in the age categories of 16 years of age and younger and 18-24 years of age demonstrated higher rates of postpartum depression (Boyce \& Hickey, 2005; Mayberry, Horowitz, \& Declercq, 2007). Maternal age was collected as a continuous variable to enable the investigator to calculate mean maternal age. Participants were asked to fill in their age on the demographic sheet. 
Infant age

Infant age or postpartum period of time has been examined in the research. Postpartum depressive symptoms have been reported by women as early as a few weeks postpartum and up to two years after birth of their infant (Beck, 2008, part 1; Horowitz \& Goodman, 2004; Mayberry, Horowitz, \& Declercq, 2007; Ugarriza \& Robinson, 1997). Infant age was collected as a continuous variable to determine the specific postpartum time period at completion of the questionnaires.

Number of children

Number of children has been examined in the research with conflicting results. In some studies, having only one child was positively correlated with postpartum depression (Eberhard-Gran, Eskild, Tambs, Samuelsen, \& Opjordsmoen, 2002; Horowitz \& Goodman, 2004). One study found a higher rate of postpartum depression in women with two children (Mayberry, Horowitz, \& Declercq, 2007).Number of children was collected as a continuous variable.

\section{Race/Ethnic Group}

Postpartum depression incidence is congruent among various races and ethnic groups in the literature (Beck, 2008, part 1; Mayberry, Horowitz, \& Declercq, 2007). Current research studies report inconsistent findings of postpartum depression incidence in U.S. and foreign born mothers (Goyal, Murphy, \& Cohen, 2006; Huang, Wong, Ronzio, \& Yu, 2007). Race/ethnic group was collected as a categorical variable.

Infant feeding method and satisfaction

Several studies have demonstrated infant feeding method as a predictor of postpartum depression. Women that are dissatisfied with their feeding method or women that bottle feed demonstrated higher rates of postpartum depression (Dennis, Janssen, \& Singer, 2004; Eberhard-Gran, 
Eskild, Tambs, Samuelsen, \& Opjordsmoen, 2002). Participants in the study were given three options related to feeding method: breastfeeding, bottle feeding, and breast and bottle feeding. All participants were also asked if they were satisfied with their current feeding method. Infant feeding method was collected as a categorical variable and infant feeding method satisfaction was collected as a dichotomous variable.

\section{Marital Status}

There was no research evidence to support the impact of marital status on postpartum depression or attitudes toward help seeking. For this research, marital status was collected as a categorical variable with five options for participants to select including single, married, divorced, widowed, and living with partner.

\section{History of Depression}

The relationship between history of depression and the incidence of postpartum depression has been demonstrated in the literature. History of depression is predictive of postpartum depression in a number of studies (Dennis, Janssen, \& Singer, 2004; Eberhard-Gran, Eskild, Tambs, Samuelsen, \& Opjordsmoen, 2002; Horowitz \& Goodman, 2004). In this study, history of depression, a categorical variable, was reported by women on the demographic sheet as a yes or no response.

\section{Educational level}

One research study reported that postpartum women with a high school education and those that did not complete high school were at a higher risk for postpartum depression than women with higher levels of education (Mayberry, Horowitz, \& Declercq, 2007). There is no research evidence to support the relationship between educational level and attitudes toward help seeking. Participants were asked to report on level of education on the demographic sheet. Education level was collected as a 
categorical variable with options including "less than high school, high school graduate, some college, and four year degree or more."

Partner/family support

Partner/family support has been reported as a significant predictor of postpartum depression. Women with positive partner support have a decreased incidence of postpartum depression (Dennis, Janssen, \& Singer, 2004; Horowitz \& Goodman, 2004; O'Hara \& Swain, 1996). For this study, partner/family support was an ordinal variable with five possible options. Participants were asked to rate the support of their partner/family on a 5 point Likert-type scale with " 1 " indicating no support at all and " 5 " indicating that their partner is extremely supportive.

\section{Procedure}

\section{Data Collection}

Approval from the Institutional Review Board of West Virginia University was obtained.

Postpartum women with infants between the ages of birth to one year of age were recruited during the well baby visits at the pediatric office. A brief explanation of the research study was provided along with a written cover letter including researcher contact information (Appendix A). A waiver of a signed consent form was requested and granted for this research study to protect participant anonymity. The demographic sheet, PDSS and the ATSPPH-SF were provided to all participants to complete (Appendices B, C, \& D). The questionnaires did not contain any identifying information. The demographic sheet and questionnaires were returned in a sealed envelope and collected by the researcher. Upon completion of the demographic sheet and questionnaires, all participants were given a list of postpartum depression support groups in the local area (Appendix E). 


\section{Data Analysis}

Data were analyzed using the Statistical Package for Social Sciences (SPSS) Graduate Pack, version 18.0, computer software program. Descriptive statistics were used to describe the study sample including maternal age, infant age, race/ethnic group, number of children, infant feeding method, satisfaction with feeding method, marital status, history of depression, educational level, and partner/family support. Measures of central tendency and variability were calculated for all continuous variables (maternal age, infant age, number of children) and frequencies and percentages were calculated for categorical variables (race/ethnic group, infant feeding method, satisfaction with feeding method, marital status, history of depression, and educational level) and ordinal variables (partner/family support).

Aim 1: To identify the incidence and presence of postpartum depressive symptoms among new mothers in the first year postpartum. Descriptive statistics were used to identify the incidence and severity of postpartum depression from the scores on the PDSS. Frequencies and percentages were presented for each of the possible categories including no depressive symptoms and mild or major depressive symptoms.

Aim 2: To examine differences in attitudes toward help seeking between postpartum women with no depressive symptoms and postpartum women with mild or major depressive symptoms. The scores on the ATSPPH-SF were examined and differences were determined among the scores on the PDSS for depression severity using the independent sample t-test. The t-test is used to determine differences in groups when the independent variable is at the categorical level and the dependent variable is at the continuous level of measurement. In this study, depression severity was a categorical variable and had two levels including no depressive symptoms and mild or major depressive symptoms. 
The ATSPPH-SF score was the dependent, continuous variable with higher scores indicating more positive attitudes toward help seeking.

Aim 3: To examine differences in attitudes toward help seeking among postpartum women with depressive symptoms that seek help and those with depressive symptoms that do not seek help. The scores on the ATSPPH-SF were examined and differences were determined between postpartum women with depressive symptoms that sought help and those that did not seek help using the independent ttest. The independent t-test is used to determine differences between group means. In this study, the mean scores on the ATSPPH-SF were calculated and differences were determined between the group of postpartum women with depressive symptoms that sought help and the group of postpartum women that did not seek help.

Aim 4: Describe the relationship among selected socio-demographic factors, presence of depressive symptoms, and attitudes toward help seeking. The relationships among the demographic variables (maternal age, infant age, number of children, satisfaction with feeding method, history of depression, and help seeking), the presence of depressive symptoms, and the ATSPPH-SF scores were examined using Kendall's tau. Maternal age, infant age, and the ATSPPH-SF scores were entered as continuous variables. Number of children was entered as a dichotomous variable (first time mothers and experienced mothers) along with satisfaction of feeding method, history of depression, and help seeking. PDSS scores were dichotomized into two categories (no depressive symptoms and mild or major depressive symptoms). Variables that demonstrated a significant relationship with ATSPPH-SF scores were entered into a linear regression model to predict ATSPPH-SF scores.

Differences in the scores on the ATSPPH-SF were determined between the various categorical demographic variables with three or more levels using the Analysis of Variance test. The ANOVA is used to determine differences when the dependent variable is continuous and the independent variable is 
categorical with three or more levels. These demographic variables included marital status, infant feeding method, and educational level. Race/Ethnic group was not omitted due to the homogeneous findings in this sample of women. Partner/family support, an ordinal variable, was correlated with the ATSPPH-SF scores using the Spearman rho statistical test. The Spearman rho test is used when comparing a continuous variable with an ordinal variable. In this study, the ATSPPH-SF scores were continuous and the partner/family support rating (1 to 5) was an ordinal variable. Scores on the ATSPPHSF were correlated with the partner/family support rating. 


\section{Chapter Four: Results}

This research study used a descriptive correlational design to investigate the relationship among attitudes toward help seeking, presence of depressive symptoms, and selected demographic variables in postpartum women during the first year after birth. This chapter presents the findings and summarizes the statistical analyses related to the aims of this research.

\section{Description of the Sample}

A convenience sample for this study consisted of 130 postpartum women who were recruited from a pediatric office in Western Pennsylvania between August 2010 and January 2011. All women who participated in this research study met the inclusion criteria. All women completed the necessary study instruments and no subjects were dropped from the study for incomplete data. A sample of 130 participants is sufficient to detect a medium effect size and a power of .8 based on an alpha of .05 (Tabachnick \& Fidell, 2007).

Postpartum women who participated in this study ranged in age from 18 to 47 with a mean age of 29.73 years $(S D=5.56)$. Infant ages ranged from 1 week to 12 months with a mean infant age of 6.09 months $(S D=3.89)$. Forty $(31 \%)$ of the infants were between 0-3 months, $36(28 \%)$ were between $4-6$ months, 26 (20\%) were between 7-9 months, and 28 (21\%) were between 10-12 months of age. Number of children ranged from 1-8 with a mean of 2 children $(S D=1.26)$. Fifty-eight $(44.6 \%)$ of the participants were first time mothers and the remaining $72(55.4 \%)$ had more than one child. A majority of women were married $(75.4 \%)$ and all participants were white (100\%), reflecting the ethnic population in the community. A majority of women bottle fed their infants (59.2\%) and most women were satisfied with their method of infant feeding (93.8\%). A majority of the women in this sample had at least some college level education (73.3\%). Partner/family support was rated from 1-5, with 1 indicating no support 
and 5 indicating extreme support. Postpartum women in this sample rated partner support favorably with a mean rating of $4.52(S D=.82)$. Thirty-eight $(29.2 \%)$ women reported a history of depression and $23(17.7 \%)$ sought care or treatment for depressive symptoms since the birth of their baby.

Comprehensive sample demographic information is displayed in Table 1.

Table 1 Sample demographics

\begin{tabular}{|c|c|c|}
\hline Demographic Variable & Frequency & Percentage \\
\hline \multicolumn{3}{|l|}{ Maternal age (years) } \\
\hline $18-22$ & 9 & 6.8 \\
\hline $23-27$ & 43 & 33 \\
\hline $28-32$ & 39 & 30 \\
\hline $33-37$ & 27 & 21 \\
\hline $38-42$ & 10 & 7.7 \\
\hline 43 and over & 2 & 1.5 \\
\hline \multicolumn{3}{|l|}{ Infant age (months) } \\
\hline $0-3$ & 40 & 31 \\
\hline $4-6$ & 36 & 28 \\
\hline 7-9 & 26 & 20 \\
\hline $10-12$ & 28 & 21 \\
\hline \multicolumn{3}{|l|}{ Number of children } \\
\hline First time mothers & 58 & 44.6 \\
\hline Experienced mothers & 72 & 55.5 \\
\hline \multicolumn{3}{|l|}{ Marital status } \\
\hline Single & 32 & 10 \\
\hline Married & 98 & 75.4 \\
\hline Divorced & 3 & 2.3 \\
\hline Living with partner & 16 & 12.3 \\
\hline
\end{tabular}




\begin{tabular}{|c|c|c|}
\hline Widowed & 0 & 0 \\
\hline White & 130 & 100 \\
\hline Black/African American & 0 & 0 \\
\hline Hispanic/Latino & 0 & 0 \\
\hline Asian & 0 & 0 \\
\hline American Indian/Alaskan & 0 & 0 \\
\hline \multicolumn{3}{|l|}{ Native Hawaiian/Pacific } \\
\hline \multicolumn{3}{|l|}{ Infant Feeding Method } \\
\hline Breast & 32 & 24.6 \\
\hline Bottle & 77 & 59.2 \\
\hline Breast and Bottle & 21 & 16.2 \\
\hline \multicolumn{3}{|l|}{ Satisfaction with feeding } \\
\hline Yes & 122 & 93.8 \\
\hline No & 8 & 6.2 \\
\hline \multicolumn{3}{|l|}{ Educational Level } \\
\hline$<$ High school & 1 & .8 \\
\hline High school graduate & 35 & 26.9 \\
\hline Some college & 48 & 36.9 \\
\hline Four year college or more & 46 & 35.4 \\
\hline \multicolumn{3}{|l|}{ Partner/Family support (rating) } \\
\hline 1 & 1 & .8 \\
\hline 2 & 4 & 3.1 \\
\hline 3 & 9 & 6.9 \\
\hline 4 & 29 & 22.3 \\
\hline 5 & 87 & 66.9 \\
\hline
\end{tabular}


History of depression

Yes

No

Help Seeking for depressive symptoms

Yes

No
38

92

23

107
29.2

70.8

17.7

82.3

Findings

Aim 1: Identify the incidence and presence of postpartum depressive symptoms in a sample of new mothers during the first year postpartum.

Participants completed the Postpartum Depression Screening Scale (PDSS) as a measure of the absence or presence of depressive symptoms. Scores on the PDSS ranging from 0-59 reflected participants with normal postpartum adjustment or no depressive symptoms. Scores ranging from 60-79 reflected women with mild depressive symptoms and scores equal to or greater than 80 reflected women with major depressive symptoms. Scores for this sample ranged from 35-148 with a mean of $67.04(S D=24.87)$. Sixty-six $(50.8 \%)$ women in this sample experienced no depressive symptoms, 35 (26.9\%) experienced mild depressive symptoms, and 29 (22.3\%) experienced major depressive symptoms. For purposes of this study, PDSS scores were collapsed into the two categories to provide adequate numbers of participants in each group for statistical analyses. The two collapsed categories include the group of women with no depressive symptoms and the group of women with minor or major depressive symptoms (See Table 2). 
Table 2 Presence of depressive symptoms (PDSS Scores) N = 130

\begin{tabular}{lcc}
\hline Depressive symptoms (PDSS score) & Frequency & Percentage \\
\hline No depressive symptoms (0-59) & 66 & 50.8 \\
$\begin{array}{l}\text { Minor or major depressive } \\
\text { symptoms (60-175) }\end{array}$ & 64 & 49.2 \\
\hline
\end{tabular}

Aim 2: Examine differences in attitudes toward help seeking in a sample of postpartum women with or without depressive symptoms.

The mean scores on the Attitudes Toward Seeking Professional Psychological Help Short Form scale (ATSPPH-SF) were analyzed to determine differences between the two groups of postpartum women with or without depressive symptoms using the independent sample t-test. Higher scores on the ATSPPH-SF are indicative of more positive attitudes toward help seeking. ATSPPH-SF scores in this sample ranged from 5 to 30 with a mean score of $22.69(\mathrm{SD}=5.589)$. The independent samples t-test was used to determine differences between group means when one variable (dependent) is at a continuous level of measurement and the other variable (independent) is at a categorical level of measurement. The assumptions of normal distribution and homogeneity of variance were assessed in these samples. The Levene's test yielded a significance level larger than $.05(p=.110)$ indicating that the assumption of equal variances was not violated. $Q-Q$ plots and histograms were somewhat normally distributed. Sample sizes of each group were greater than 30 so the parametric t-test was utilized. Analysis demonstrated a significant difference in ATSPPH-SF scores for postpartum women with no depressive symptoms ( $M=25.33, S D=4.54)$ and postpartum women with mild or major depressive symptoms $[M=19.97, S D=5.28 ; t(128)=6.22, p<.001]$. The significant difference in scores on the ATSPPHSF indicated higher, more positive, attitudes toward help seeking among women with no depressive 
symptoms and lower, more negative, attitudes toward help seeking among women with depressive symptoms (See Table 3).

Table 3: Differences in attitude scores between postpartum women with and without depressive symptoms $(\mathrm{N}=130)$

\begin{tabular}{|c|c|c|c|c|c|}
\hline \multicolumn{6}{|l|}{ Attitude Scores } \\
\hline & $\mathrm{N}$ & Mean & SD & $\mathrm{t}$ & df \\
\hline \multicolumn{6}{|c|}{ Presence of depressive symptoms } \\
\hline No & 66 & 25.33 & 4.538 & $6.219 * * *$ & 128 \\
\hline Yes & 64 & 19.97 & 5.279 & & \\
\hline
\end{tabular}

Aim 3: Examine differences in attitudes toward help seeking in a sample of postpartum women with depressive symptoms that seek help and those with depressive symptoms that do not seek help.

The scores on the ATSPPH-SF scale for only the postpartum women with depressive symptoms were analyzed to determine differences in mean attitude scores between postpartum women that sought help for depressive symptoms and those that did not seek help for depressive symptoms. The samples were not normally distributed and one group had a sample size of less than 30 , therefore, the non-parametric Mann-Whitney U Test was utilized. Results demonstrated a significant difference in mean help seeking attitude scores between postpartum women with depressive symptoms that sought help and those women with depressive symptoms that did not seek help. Women with depressive symptoms that sought help had more positive attitudes toward help seeking than women with depressive symptoms that did not seek help (See Table 4). 
Table 4: Differences in attitude scores between postpartum women with depressive symptoms that seek help and those that do not seek help $(\mathrm{N}=64)$

\begin{tabular}{lcccc}
\hline $\begin{array}{l}\text { Attitude Scores in women with depressive } \\
\text { symptoms }\end{array}$ & N & Median & $\begin{array}{c}\text { Mann- } \\
\text { Whitney U }\end{array}$ & Z \\
\hline Help seeking for depressive symptoms & & & & \\
Yes & 16 & 45.34 & 178.50 & $-3.20^{* * *}$ \\
$\quad$ No & 48 & 28.22 & & \\
& & &
\end{tabular}

$* * * p<.001$

Aim 4: Describe the relationship among selected socio-demographic factors (maternal age, infant age, race/ethnic group, number of children, infant feeding method, satisfaction with feeding method, marital status, history of depression, educational level, and partner/family support), presence of depressive symptoms, and attitudes toward help seeking scores in this sample of postpartum women.

Self-reported demographic variables and the PDSS scores were compared to the ATSPPH-SF scores. The Q-Q plots and bi-variate scatterplots were run to determine normal distributions and linear relationships among the variables. A majority of the variables were not normally distributed therefore violating the assumptions of parametric testing. The relationships among the sociodemographic variables, PDSS scores, and attitudes toward help seeking were analyzed using Kendall's tau due to the violation of the assumption of normality for a majority of the variables (Munro, 2005). Maternal age, infant age, and ATSPPH-SF scores were entered as continuous variables. Number of children was dichotomized into two groups. Women with one child were classified as "first time mothers" and women with two or more children were classified as "experienced mothers" to determine differences in ATSPPH-SF scores between the groups. Educational level was collapsed from four groups into three groups due to small, unequal group sample sizes. Women with less than high school and high school completion were classified as "high school or less," women with some college remained classified as "some college," and women with a four year college degree or more remained classified as "four or 
more years of college." PDSS scores were entered as a dichotomous variable with scores of 0-59 indicating no depressive symptoms and scores of 60-175 indicating mild or major depressive symptoms. Marital status, infant feeding method, satisfaction with feeding method, history of depression, and help seeking were also entered as categorical variables. Race was omitted due to the homogeneous findings in this sample of women. The overall correlations are presented in Table 5.

There was a significant, negative correlation between scores on the PDSS and scores on the ATSPPH-SF $\quad(r=-.464 ; p<.001)$. Postpartum women with lower scores on the PDSS demonstrated more positive attitudes toward help seeking than postpartum women with higher PDSS scores indicating that women with no depressive symptoms had more positive attitudes toward help seeking than women with minor or major depressive symptoms. Maternal age was significantly, negatively correlated with scores on the PDSS $(r=-.207, p<.01)$. Younger women had higher scores on the PDSS than older women. There was a significant, positive correlation between history of depression and seeking help for depressive symptoms $(r=.588, p<.001)$. Postpartum women with a history of depression were more likely to seek help for depressive symptoms than women who did not have a history of depression. History of depression was also significantly, negatively correlated with presence of depressive symptoms $(r=-213, p<.05)$. Women with a history of depression had higher scores on the PDSS, indicating presence of depressive symptoms, than women without a history of depression.

Since maternal age was a normally distributed variable, the Pearson correlation coefficient was utilized to analyze the relationship between maternal age and ATSPPH-SF scores. There was a significant, positive correlation between maternal age and attitudes toward help seeking $(r=.191$, $p<.05)$. Older postpartum mothers had more positive attitudes toward help seeking than younger mothers. 
Table 5: Inter-correlations for socio-demographic variables, PDSS scores and ATSPPH-SF scores (Kendall's tau)

\begin{tabular}{|c|c|c|c|c|c|c|c|c|}
\hline Variable & $\begin{array}{l}\text { ATSPPH- } \\
\text { SF scores }\end{array}$ & $\begin{array}{l}\text { Maternal } \\
\text { age }\end{array}$ & $\begin{array}{l}\text { Infant } \\
\text { age }\end{array}$ & $\begin{array}{c}\text { \# of } \\
\text { children }\end{array}$ & $\begin{array}{l}\text { Satisfaction } \\
\text { feeding }\end{array}$ & $\begin{array}{l}\text { History of } \\
\text { depression }\end{array}$ & Help seeking & $\begin{array}{l}\text { PDSS scores } \\
\text { Dichotomous }\end{array}$ \\
\hline $\begin{array}{l}\text { ATSPPH-SF } \\
\text { scores }\end{array}$ & - & .105 & -.017 & .082 & -.078 & -.066 & -.113 & $-.464 * * *$ \\
\hline Maternal age & & - & .003 & $.380 * * *$ & .105 & .128 & .120 & $-.207^{* *}$ \\
\hline $\begin{array}{c}\text { Infant } \\
\text { age }\end{array}$ & & & - & -.016 & -.144 & -.058 & -.023 & .048 \\
\hline \# of children & & & & - & .103 & -.099 & .066 & -.154 \\
\hline $\begin{array}{l}\text { Satisfaction } \\
\text { feeding }\end{array}$ & & & & & - & -.047 & $-.217^{*}$ & .068 \\
\hline $\begin{array}{l}\text { History of } \\
\text { depression }\end{array}$ & & & & & & - & $.588 * * *$ & $-.213^{*}$ \\
\hline Help seeking & & & & & & & - & $-.189^{*}$ \\
\hline $\begin{array}{l}\text { PDSS scores } \\
\text { Dichotomous }\end{array}$ & & & & & & & & - \\
\hline
\end{tabular}

$* \mathrm{p}<.05,{ }^{* *} \mathrm{p}<.01, * * * \mathrm{p}<.001$ 
Partner/family support was correlated with PDSS scores and ATSPPH-SF scores using the Spearman's rho statistical test due to the ordinal nature of the variable and the violation in the assumption of normal distribution. Partner/family support was not significantly correlated with the scores on the ATSPPH-SF $(r=.135, p=.125)$ but was significantly, negatively correlated with the PDSS scores $(r=-.302, p<.001)$. Women with lower perceived partner or family support had higher scores on the PDSS indicating minor or major depressive symptoms.

The one way analysis of variance (ANOVA) was used to compare the mean ATSPPH-SF scores and mean PDSS scores between variables with three or more levels. These included marital status, infant feeding method, and educational level. There were no significant differences in mean ATSPPH-SF scores or PDSS scores by marital status (single, married, divorced, widowed, and living with partner), by infant feeding method (breast, bottle, and breast and bottle), or by education level (high school or less, some college, and four year degree or more).

Variables that demonstrated a significant relationship with ATSPPH-SF scores in the bi-variate analysis, including maternal age and PDSS scores, were entered into a linear regression model to predict ATSPPH-SF scores. Prior to interpretation, tests to check the assumptions for multiple regression were performed. To test for multicollinearity, the independent variables were checked for some relationship, preferably less than .9 (Pallant, 2005). Maternal age weakly correlated with the ATSPPH-SF scores (.191) while presence or absence of depressive symptoms moderately correlated with the ATSPPH-SF scores (-.482). These correlation values do not violate the assumption of multicollinearity or singularity. Tolerance and VIF values were also evaluated and confirm the absence of multicollinearity.

Testing the assumptions of normality, linearity, homoscedasticity, and outliers was achieved through inspection of residuals in the scatterplot and the normal probability plot of regression standardized residuals. The points along the normal probability plot were reasonably aligned in a 
straight diagonal line from bottom left to top right. In the scatterplot, there were no distinct patterns or extreme outliers present therefore, there were no violations to the assumptions of normality, linearity, homoscedasticity, and outliers in this model (Appendices F \& G).

The $R^{2}$ value was analyzed to determine the amount of variance in ATSPPH-SF scores explained by the variables in this model. The variables of presence of depressive symptoms and maternal age explained $23.9 \%$ of the variance in the ATSPPH-SF scores. However, the independent variable of depressive symptoms contributed significantly to the prediction of the scores on the ATSPPH-SF scale while maternal age did not make a significant contribution to the prediction of these scores (See Table 6).

Table 6: Multiple regression analysis for variables predicting attitudes toward help seeking $(\mathrm{N}=130)$

\begin{tabular}{lccccc}
\hline Variable & B & SEb & Beta & t & $p$ \\
\hline PDSS scores & & & & & \\
Maternal age & -5.147 & .886 & -.462 & -5.810 & .000 \\
\hline
\end{tabular}

$\mathrm{R}^{2}=.239, \mathrm{~F}=19.933, \mathrm{p}<.001$ 


\section{Chapter Five: Discussion}

This chapter presents a summary of the research findings and the relationship of these findings to the model that guided this study. Findings will also be compared and contrasted to previous related research. Limitations, implications for clinical practice, and recommendations for future research will also be included.

\section{Major Findings}

\section{Postpartum Depression}

In the sample of postpartum women in this research study, depressive symptom rates were significantly higher than the overall postpartum depression rate of $10-15 \%$ reported in the literature (Beck, 2008, part 1; Ugarriza \& Robinson, 1997). Approximately half of the women in the sample (50.8\%) experienced no depressive symptoms. However, of the remaining women in the sample, $26.9 \%$ experienced mild depressive symptoms and $22.3 \%$ experienced major depressive symptoms. Overall rates of major depression range from 1-5.9\% and combined minor and major depression range from 6.5$12.9 \%$ in the current literature (Gaynes, et al., 2005). There are few studies that report similar high rates of minor and major depression rates among postpartum women.

Horowitz and Goodman (2004) reported an overall rate of depression of $27.4 \%$ to $41.9 \%$ during several time periods in the first two years postpartum. Price and Proctor (2009) found that $36 \%$ of women in their study met the criteria for major and minor depression with $13 \%$ meeting the diagnostic criteria for major depression alone. Austin, Hadzi-Pavlovic, Priest, Reilly, Wilhelm, Saint, and Parker (2010) reported a major depression rate of $32.8 \%$ and a minor depression rate of $26.4 \%$ in their sample of postpartum women. Each of these studies used different data collection methods and time periods to screen for depression. Some research studies screened postpartum women at a given point in time after 
birth while other studies screened women over a period of time after birth. Overall, higher rates of postpartum depression were noted in research studies that examined postpartum depressive symptoms over a period of time as opposed to a given point in time after birth (Austin, Hadzi-Pavlovic, Priest, Reilly, Wilhelm, Saint, \& Parker, 2010; Horowitz \& Goodman, 2004; Price \& Proctor, 2009). A possible explanation for the higher rate of postpartum depressive symptoms in this study could be related to the screening of postpartum women throughout the first year after birth. In the literature, studies that used self-report of depression symptoms through a confidential questionnaire yielded higher rates of depression than telephone or face to face interviewing (Horowitz, Murphy, Gregory, \& Wojcik, 2011). This current study utilized a confidential, anonymous questionnaire to screen for postpartum depressive symptoms as in studies that used similar methods of screening and reported higher depression rates.

It is very difficult to compare results across research studies due to the lack of standardization of screening scales and data collection points. Methods for postpartum depression screening reported in the literature include self-report questionnaires, telephone/face to face questioning, and diagnostic interviews (Beck, 2008, part 2; Gaynes, et al., 2005).Some research studies use specific data collection times to determine depressive rate frequencies after birth. Other research on screening for postpartum depression occurred over a one to two year period after birth (Boyce \& Hickey, 2005; Dennis, Janssen, \& Singer, 2004; Mayberry, Horowitz, \& Declercq, 2007). Although prior research demonstrated an overall postpartum depression rate of $10-15 \%$, increased rates of depressive symptoms in this study could be explained by the broader data collection time frame of one year after birth and the use of a self-report, confidential, anonymous method of screening.

There are also population samples of postpartum women who demonstrate higher rates of depression in the literature. In particular, several research studies reported a higher incidence of postpartum depression among low income postpartum women (Boyce \& Hickey, 2005; Horowitz \& 
Goodman, 2004; Price \& Proctor, 2009). Income was not included in the demographic information that was collected for the sample in this study. While women in this study were cared for in a private pediatrician's office in a suburban area, and were in general well educated, given the uncertain economic times during which this study took place, concerns over economics might have been a contributing factor to the higher incidence of depressive symptoms in this study.

\section{Attitudes Toward Help Seeking}

This study is one of the few studies to evaluate postpartum women's attitudes toward help seeking. Attitudes toward help seeking can either facilitate or inhibit women from getting help when depressed (Barney, Griffiths, Jorm, \& Christensen, 2006; Vogel, Wade, Wester, Larson, \& Hackler, 2007). In this study, women with minor or major depressive symptoms had significantly more negative attitudes toward seeking professional help.

A majority of adults with depression that do not seek help demonstrate more negative attitudes toward help seeking. Findings in women suggest that negative attitudes and beliefs regarding help seeking result in significant barriers to help seeking (Bilszta, Ericksen, Buist, \& Milgrom, 2010). Several variables have been correlated with more negative attitudes toward help seeking in adults with depression. Shame and stigma regarding depression seem to produce the most negative attitudes toward help seeking in adults with depression (Jesse, 2008; McCarthy \& McMahon, 2008). Older adults tend to have more negative stereotypes about depression which result in significant underutilization of health care services for depression (Segal, Coolidge, Mincic, \& O'Riley, 2005). Lack of trust, failure to disclose feelings, and perceived negative expectations also lead to more negative attitudes toward help seeking (Jesse, 2008; Vogel \& Wester, 2003). There are limited studies that investigate factors that influence attitudes toward help seeking in postpartum women. Postpartum women with considerably more negative attitudes toward help seeking report feelings of failure as a new mother, stigma 
associated with the diagnosis of depression, and perception that they could help themselves (Bilszta, Ericksen, Buist, \& Milgrom, 2010; McCarthy \& McMahon, 2008). More positive attitudes toward help seeking are associated with knowing someone that sought help for depression, being prompted to seek help for depression, and adequate support and resources from friends, family and professionals (Vogel, Wade, Wester, Larson, \& Hackler, 2007).

In this study, women with depressive symptoms who sought help since the birth of their baby had more positive attitudes toward help seeking than women with depressive symptoms that had not sought help. Empirical support for more positive attitudes toward help seeking in adults that have previously received professional help is found in men and women with depression (Vogel \& Wester, 2003). Previous counseling experience is a consistent predictor of help seeking attitudes. More positive attitudes are reported in adults with depression that were either prompted to seek help or knew someone that had sought help for depression (Vogel, Wade, Wester, Larson, \& Hackler, 2007). Ciarrochi and Deane (2001) reported that most adults that had previously experienced help for depression were more likely to utilize services again if they were needed. Postpartum women with depression reported a change in attitudes toward help seeking once treated for depression (McCarthy \& McMahon, 2008). These women experienced a change in their understanding and perception of postpartum depression after initial discussions with a health care professional. Discussions with other postpartum women with depression decreased the stigma and feelings of shame that most women reported prior to open discussions about their depression.

\section{Relationship of Demographic Variables, Presence of Depressive Symptoms, and ATSPPH-SF scores}

Demographics and presence of depressive symptoms

In this sample, maternal age, history of depression and partner/family support were correlated with presence of depressive symptoms. Younger women demonstrated more depressive symptoms than 
older women. Postpartum women with a history of depression demonstrated more depressive symptoms than women without a history of depression. Women in this sample with lower perceived partner/family support demonstrated more depressive symptoms than women with higher perceived support. The findings of this study were generally consistent with previous research studies on risk factors and predictors of depression.

Infant age, number of children, marital status, infant feeding method, satisfaction with feeding method, and educational level were not significantly correlated with depressive symptom severity. Previous research studies were varied in reports of associations between these variables and postpartum depression. A number of research studies have found an association between maternal age and depressive symptom severity (Boyce \& Hickey, 2005; Mayberry, Horowitz, \& Declercq, 2007). Empirical support for the association between a history of depression and postpartum depression was found in many research studies on postpartum depression risk factors and predictors (Beck, 2008, part 1; Boyce \& Hickey, 2005; Dennis, Janssen, \& Singer, 2004; Eberhard-Gran, Eskild, Tambs, Samuelsen, \& Opjordsmoen, 2002; Howell, Mora, \& Leventhal, 2006; O'Hara \& Swain, 1996; Oppo, Mauri, Ramacciotti, Camilleri, Banti, Borri, Rambelli, Montagnani, Cortopassi, Bettini, Ricciardulli, Montaresi, Rucci, Beck, \& Cassano, 2009). A majority of research studies also provide support for the association between perceived social support and postpartum depression with lower perceived support related to increased postpartum depression (Beck, 2008, part 1; Boyce \& Hickey, 2005; Dennis, Janssen, \& Singer, 2004; Eberhard-Gran, Eskild, Tambs, Samuelsen, \& Opjordsmoen, 2002; Howell, Mora, \& Leventhal, 2006; O'Hara \& Swain, 1996).

Number of children, infant feeding method, feeding method satisfaction, educational level, and marital status have all been found to be related to postpartum depression in previous research studies. Postpartum women with only one child demonstrated significantly higher rates of depression than 
women with two or more children in a number of studies (Eberhard-Gran, Eskild, Tambs, Samuelsen, \& Opjordsmoen, 2002; Mayberry, Horowitz, \& Declercq, 2007). Women that did not breastfeed or who were dissatisfied with their feeding method also demonstrated higher rates of depression (Dennis, Janssen, \& Singer, 2004; Eberhard-Gran, Eskild, Tambs, Samuelsen, \& Opjordsmoen, 2002). Educational level was negatively correlated with postpartum depression in groups of women with less than a high school education (Horowitz, Murphy, Gregory, \& Wojcik, 2011; Howell, Mora, Horowitz, \& Leventhal, 2005; Mayberry, Horowitz, \& Declercq, 2007). Previous studies support the association between young maternal age and higher rates of postpartum depression (Beck, 2008, part 1). Findings in this study were not consistent with the literature for these associations between variables. Sample sizes in each of the categories were sometimes too small for appropriate analysis. In addition, little variability was seen in some of these categories in the current study, limiting ability to detect relationships.

\section{Demographics and ATSPPH-SF scores}

The two variables that correlated with attitudes toward help seeking were maternal age and depressive symptom severity. Older postpartum women had more positive attitudes toward help seeking than younger women and women with minor or major depressive symptoms had more negative attitudes toward help seeking than women without depressive symptoms. There are very few studies in the literature that examine attitudes toward help seeking in postpartum women. Overall, adults with depression have negative attitudes toward help seeking (Barney, Griffiths, Jorm, \& Christensen, 2006; Bilszta, Ericksen, Buist, \& Milgrom, 2010; Vogel, Wade, Wester, Larson, \& Hackler, 2007). Empirical support for the correlation between age and help seeking attitudes was found in a few studies on adults with depression (Hickie, Luscombe, Davenport, Burns, \& Highet, 2007; MacKenzie, Gekoski, \& Knox, 2006). Generally, older women tend to have more positive attitudes toward help seeking than older males and younger male or female adults (MacKenzie, Gekoski, \& Knox, 2006). There are no studies to 
support the correlation between age and help seeking attitudes among postpartum women however, the findings from this study are supported by the research on women with depression. Older women have greater life experience and tend to recognize and accept the diagnosis of depression more readily than younger adults that lack this life experience (Barney, Griffiths, Jorm, \& Christensen, 2006; Halter, 2004).

\section{Study Findings and the Model of Help Seeking}

The findings of this study support the relationship between postpartum depressive symptoms and attitudes toward help seeking. The conceptual model of help seeking in postpartum women guided the study to evaluate which women will have attitudes that may hinder them from seeking help. Both maternal age and PDSS scores were entered into the regression model to predict ATSPPH-SF scores. PDSS scores contributed significantly to the variance in the ATSPPH-SF scores. Maternal age did not make a significant contribution to the variance in the ATSPPH-SF scores.

In the Theory of Planned Behavior, individuals act in accordance with their intentions, while intentions are influenced by attitudes toward the behavior (Ajzen, 1991). Overall, the stronger the intention to perform the behavior, the more likely the behavior is likely to occur. Vogel, Wester, and Boysen (2005) found that attitudes significantly predict the variance in the intent to seek help for interpersonal problems. Similar to the findings in this study, a recent study by Bilstzta and colleagues (2010) supports the association between attitudes and help seeking in women with postpartum depression. Findings from previous studies suggest that women with postpartum depression have more negative attitudes toward help seeking and that those attitudes resulted in a significant barriers to actual help seeking (Bilszta, Ericksen, Buist, \& Milgrom, 2010). Findings from the current study support the notion that women with minor or major depressive symptoms have more negative attitudes toward help seeking. Women with depressive symptoms who did not seek help since the birth of their baby had 
more negative attitudes toward help seeking than women that were receiving help for their depressive symptoms. The Conceptual Model of Help Seeking in Postpartum Women guided the study appropriately in helping to predict which postpartum women may have attitudes that can hinder professional help seeking.

\section{Limitations}

Sample homogeneity was a significant limitation in this study. Correlation and prediction abilities were limited by the small frequencies in some categorical variables. Targeted sampling was not possible in the recruitment of subjects due to time constraints of the researcher and the pediatric practice and availability of subjects during routine infant visits in the pediatric office. The sample had little variablitity in the upper and lower extremes of maternal age, limiting the ability to analyze age extremes and their correlation with depressive symptom severity, as reported in the literature. Education level also was homogeneous; only one participant had less than a high school education, limiting the ability to analyze the impact of lower educational attainment on study variables. Small sample sizes of women with major depressive symptoms resulted in the two collapsed categories of "no depressive symptoms" and minor or major depressive symptoms", again limiting the ability to analyze relationships between study variables and severity of depressive symptoms. Another major limitation of this study was the homogeneity of ethnic/racial categories in the sample. All participants in this study were white, reflecting the population in the community. Generalizability was limited due to the homogeneous sampling of participants in this study.

An additional limitation in data collection included self-report of depressive symptoms by the participants. These self reports were not confirmed with any interview process. Given the sensitive nature of depression and the associated symptoms, a self report method was preferred and yielded a 
higher depression rate than the literature, however self report methods raise concerns over accuracy and validity.

The last limitation involves the use of the Ajzen's Theory of Planned Behavior to guide the research study. Two of the three antecedents of behavior were not measured therefore, missing some of the predictors of actual help seeking behavior including social norms, and perceived behavioral control. Since intentions to seek help are such a strong predictor of actual help seeking behavior, intentions were also excluded from measurement in this study and only attitudes toward help seeking were examined in relation to actual help seeking behavior. As a result, participants that intended to seek help but did not actually seek professional help would have been missed in this study.

Finally there is support in the literature for the association between income and depression among postpartum women. A higher incidence of postpartum depression is noted in women with low income levels. Income may have explained the higher rates of depression symptoms in this sample of women however, income levels were not included in the data collected for this study, limiting the analysis of any differences in depressive symptoms related to socioeconomic status.

\section{Implications for Clinical Practice}

The higher rates of depressive symptoms through a self-report, confidential instrument used in this study may indicate that postpartum depression occurs at a much higher rate than reported in the literature. Since postpartum depressive symptoms were noted at various time periods throughout the first postpartum year in this study, it is important to initiate and continue screening for depression throughout the first year after birth. Health care providers also need to identify women that are at a greater risk for postpartum depression for early detection and management. Women who are younger, have a history of depression, and have limited perceived partner/family support reported more depressive symptoms in this study. Additional risk factors for postpartum depression have been 
reported in the literature and include first time mothers, bottle feeding, dissatisfaction with feeding method, single or divorced marital status, less than high school education level, and lower socioeconomic status (Beck, 2008, part 1; Dennis \& Chung-Lee, 2006; Eberhard-Gran, Eskild, Tambs, Samuelsen, \& Opjordsmoen, 2002; Horowitz \& Goodman, 2004; Mayberry, Horowitz, \& Declercq, 2007).

Given the significant potential impact of postpartum depression on maternal and infant outcomes, it is imperative to be consistent and thorough in detecting and treating postpartum depression. Detection and management involve increasing awareness of the screening methods, symptoms, and management of postpartum depression by all healthcare providers that the new mother encounters. The pediatric setting can improve maternal-infant outcomes by implementing collaborative programs that address the identification of women at risk for postpartum depression and subsequent lack of help seeking behaviors. Community support groups are imperative to reduce stigma and provide education regarding screening, treatment and resources. Successful programs require the collaborative approach from the pediatric, obstetric, and psychiatric nurse practitioners who bring an expertise in best practice from each specialty. The pediatric office provides frequent interactions with new mothers during the first one to two years after birth and women report ease in discussing their concerns with pediatric health care providers. The success of this study in recruiting women from pediatric offices supports the feasibility of screening for depression in mothers during the first year after birth during well baby check-ups in the pediatric office. (Liberto, Accepted for publication).

Current legislation has the potential to influence screening practices for postpartum depression. The Mom's Opportunity to Access Health, Education, Research, and Support for Postpartum Depression Act (The Mother's Act), was developed to ensure that new mothers and their families are educated about postpartum depression, screened for symptoms, and provided with essential services, and to increase research at the National Institutes of Health on postpartum depression. The bill was introduced 
and passed in the United States House of Representatives. In 2009, the bill was introduced in the United States Senate and referred to the Senate Committee on Health, Education, Labor, and Pensions (Library of Congress, 2009-2010). In 2010, ten states had active legislation focused on postpartum depression and two states had pending legislation. Currently, New Jersey is the only state that requires mandatory screening for postpartum depression (Kozhimannil, Adams, Soumerai, Busch, \& Huskamp, 2011). Mandatory screening would improve detection rates, and could influence help seeking.

Overall, postpartum women who reported depressive symptoms demonstrated more negative attitudes toward seeking professional help in this study. In only the sample of postpartum women reporting minor or major depressive symptoms, more positive attitudes were demonstrated in women that sought help since the birth of their infant. These findings are consistent with current research that reports greater rates of help seeking in adults that have previously sought help for depression. It is imperative to promote more positive perceptions of professional help seeking in women with negative attitudes through adequate educational, support and resources for new mothers.

Identification of women at risk involves an examination into the demographic factors that increase a woman's risk for postpartum depression. Once identified, education on detection, management, and resources can be provided to these women to change negative attitudes toward professional help. Follow up of women with depressive symptoms can be achieved through phone interviews or brief interviews at future pediatric visits. Healthcare providers need to also be aware of the personal and societal attitudes that hinder postpartum women from receiving the help that they need. More effective strategies, resources, and support are needed for postpartum women with depressive symptoms to avoid long term consequences for both the mother and her infant. Early intervention of women with depressive symptoms is a necessary first step in the management of this disorder. The strong correlation between postpartum depressive symptoms and negative help seeking 
attitudes indicates the need for follow up and ongoing management in these women. A collaborative approach is necessary to improve outcomes for women and their children through early detection and management of postpartum depression at well child visits. Maternal-infant health care providers must work collaboratively with pediatric and psychiatric health care providers to improve outcomes for new mothers and their infants through proper training and knowledge of available resources.

\section{Recommendations for Future Research}

Overall, there is a gap in our knowledge of help seeking attitudes in postpartum women with depressive symptoms. Very few research studies have been conducted to identify variables that hinder postpartum women from seeking professional help. Since a majority of postpartum women with depressive symptoms do not seek help, future studies should focus on investigation of factors that inhibit help seeking or interventions that promote positive attitudes toward help seeking (McGarry, Kim, Sheng, Egger, \& Baksh, 2009; Riecher-Rossler \& Hofecker Fallahpour, 2003; Whitton, Warner, \& Appleby, 1996). A replication study in a setting that serves lower socioeconomic groups will include a broader, more diverse population sample and may identify further variables that impact help seeking. While this study found that a portion of the variance in attitudes toward help seeking was explained by depression, a variety of other variables likely explain more of the variance. These variables need to be identified and evaluated for their impact on attitudes toward help seeking if we are to be able to translate this knowledge into clinical practice. Future research on the impact of actual help seeking on maternal and infant outcomes is necessary for increasing available resources and providing funding for further programs.

Future research is needed to further evaluate the relationships between help seeking attitudes and postpartum depressive symptoms among a larger more diverse population sample. Given the high rates of depressive symptoms in this sample, investigation into variables that increase the risk of 
depressive symptoms in postpartum women is warranted. Although there were no significant correlations between the specific risk factors of marital status, education level and number of children with rates of depressive symptoms or attitudes toward help seeking in this study further evaluation is warranted in larger, more diverse population samples.

Current research studies vary greatly in the methods and settings utilized for postpartum depression screening. Consistent screening techniques and instruments would enhance comparison across research studies involving postpartum women. Generally, because postpartum women are healthy and only access healthcare services for well baby care, the pediatric setting is the only opportunity for screening and management. Efforts to improve screening require the use of screening instruments that are developed for postpartum women, are easy to use in clinical practice, and have consistent use of cut-off scores for depression identification and referral.

\section{Conclusion}

Postpartum depression is the most common complication of the postpartum period. A majority of women with depressive symptoms fail to seek help for postpartum depression. There is limited research on help seeking in postpartum women and most help seeking screening tools have not been utilized in this population of women. Screening tools focus on attitudes and intentions to seek help rather than actual help seeking. Future research is needed to identify factors that influence help seeking in postpartum women. Once identified, strategies to reduce negative help seeking attitudes should be initiated. Efforts to increase routine screening for postpartum depression in the pediatric setting should involve adequate training and education in the identification, management, resources, and support of this disorder in postpartum women. Finally, appropriate follow-up and collaborative management is imperative for positive maternal-infant outcomes. 


\section{References}

Ajzen, I. (1991). The theory of planned behavior. Organizational Behaviour and Human Decision Processes, 50, 179-211.

APA. (2000). Diagnostic and Statistical Manual of Mental Disorders text-revision (4th edition ed.). Washington, DC: American Psychiatric Association.

Austin, M. V., Hadzi-Pavlovic, D., Priest, S. R., Reilly, N., Wilhelm, K., Saint, K., et al. (2010). Depressive and anxiety disorders in the postpartum period: How prevalent are they and can we improve their detection? Archives of Women's Mental Health, 13, 395-401.

Barney, L. J., Griffiths, K. M., Jorm, A. F., \& Christensen, H. (2006). Stigma about depression and its impact on help seeking intentions. Australian and New Zealand Journal of Psychiatry, 40, 51-54.

Beck, C. T. (2002). Postpartum depression: A metasynthesis. Qualitative Health Research, 12(4), 453472.

Beck, C. T. (2008, part 1). State of the science on postpartum depression part 1. The American Jouranl of Maternal/Child Nursing, 33(2), 121-126.

Beck, C. T. (2008, part 2). State of the science on postpartum depression part 2. The American Journal of Maternal/Child Nursing, 33(3), 151-156.

Beck, C. T., \& Gable, R. (2000). Postpartum depression screening scale: Development and psychometric testing. Nursing Research, 49, 272-282.

Berggren-Clive, K. (1998). Out of the darkness and into the light: women's experiences with depression after childbirth. Canadian Journal of Community Mental Health, 17(1), 103-120.

Bilszta, J., Ericksen, J., Buist, A., \& Milgrom, J. (2010). Women's experience of postnatal depression beliefs and attitudes as barriers to care. Australian Journal of Advanced Nursing, 27(3), 44-54.

Boyce, P., \& Hickey, A. (2005). Psychosocial risk factors to major depression after childbirth. Social Psychiatry and Psychiatric Epidemiology, 40, 605-612. 
Broadhurst, K. (2003). Engaging parents and carers with family support services: What can be learned from research on help-seeking? Child and Family Social Work, 8, 341-350.

Chaudron, L. H., Szilagyi, P. G., Kitzman, H. J., Wadkins, H., \& Cornwell, Y. (2004). Detection of Postpartum Depressive Symptoms by Screening at Well-Child Visits. Pediatrics, 113(3), 551-558.

Ciarrochi, J., \& Deane, F. P. (2001). Emotional competence and willingness to seek help from professional and nonprofessional sources. British Journal of Guidance and Counseling, 29(2), 233-246.

Cohen, B. (1999). Measuring the willingness to seek help. Journal of Social Service Research, 26, 67-82.

Cox, J. L., Holden, J. M., \& Sagovsky, R. (1987). Detection of postpartum depression: Development of the 10-item edinburgh postnatal depression scale. British Journal of Psychiatry,150, 782-786.

Cusack, J., Deane, F. P., Wilson, C. J., \& Ciarrochi, J. (2006). Emotional expression, perceptions of therapy, and help seeking intentions in men attending therapy services. Psychology of Men and Masculinity, 7(2), 69-82.

Dawson, G., Frey, K., Panagiotides, H., Yamada, E., Hessl, D., \& Osterling, J. (1999). Infants of depressed mothers exhibit atypical frontal electical brain activity during interactions with mother and with a familiar, nondepressed adult. Child Development, 70(5), 1058-1066.

Dennis, C., \& Chung-Lee, L. (2006). Postpartum depression help-seeking barriers and maternal treatment preferences: a qualitative systematic review. Birth: Issues in Perinatal Care, 33(4), 323-331.

Dennis, C., Janssen, P. A., \& Singer, J. (2004). Identifying women at risk for postpartum depression in the immediate postpartum period. Acta Psychiatrica Scandinavica, 110, 338-346.

Eberhard-Gran, M., Eskild, A., Tambs, K., Samuelsen, S. O., \& Opjordsmoen, S. (2002). Depression in postpartum and non-postpartum women: prevalence and risk factors. Acta Psychiatrica Scandinavica, 106(6), 426. 
Feinberg, E., Smith, M. V., Morales, M. J., Claussen, A. H., Smith, D. C., \& Perou, R. (2006). Improving Women's Health during Internatal Periods: Developing an Evidenced-Based Approach to Addressing Maternal Depression in Pediatric Settings. Journal of Women's Health (15409996), 15(6), 692-703.

Fischer, E. H., \& Farina, A. (1995). Attitudes toward seeking professional psychological help: A shortened form and considerations for research. Journal of College Student Development, 36(4), 368-373.

Fischer, E. H., \& Turner, J. L. (1970). Orientations to seeking professional help: Developemnt and research utility of an attitude scale. Journal of Consulting and Clinical Psychology, 35(1), 79-90.

Freeman, M. P., Wright, R., Watchman, M., Wahl, R. A., Sisk, D. J., Fraleigh, L., et al. (2005). Postpartum depression assessments at well-baby visits: screening feasibility, prevalence, and risk factors. Journal of Women's Health, 14(10), 929-935.

Gaynes, B. N., Gavin, N., Meltzer-Brody, S., Lohr, K. N., Swinson, T., Gartlehner, G., et al. (2005). Perinatal depression: Prevalence, screening, accuracy, and screening outcomes summary. . Evidence Report: Technology Assessment, 119, 1-8.

Glover, L., Novakovic, A., \& Hunter, M. S. (2003). Women's needs and preferences for psychological help and support in a gynaecological outpatient service. Journal of Reproductive and Infant Psychology, 21(3), 195-206.

Goldsmith, A. E. (2007). Postpartum depression screening by family nurse practitioners. Journal of the American Academy of Nurse Practitioners, 19, 321-327.

Goodman, J. H. (2009). Women's attitudes, preferences, and perceived barriers to treatment for perinatal depression. Birth: Issues in Perinatal Care, 36(1), 60-69.

Gourash, N. (1978). Help seeking: A review of the literature. American Journal of Community Nursing, 6, 413-423. 
Goyal, D., Murphy, S. O., \& Cohen, J. (2006). Immigrant asian indian women and postpartum depression. Journal of Obstetric, Gynecologic, and Neonatal Nursing, 35(1), 98-104.

Halter, M. J. (2004). Stigma and help seeking related to depression. Journal of Psychosocial Nursing $42(2), 42-51$.

Hanna, B., Jarman, H., \& Savage, S. (2004). The clinical application of three screening tools for recognizing postpartum depression. International Journal of Nursing Practice, 10, 72-79.

Hickie, I. B., Luscombe, G. M., Davenport, T. A., Burns, J. M., \& Highet, N. J. (2007). Perspectives of young people and depression: Awareness, experiences, attitudes and treatment preferences. Early Interventions in Psychiatry, 1, 333-339.

Holopainen, D. (2002). The experience of seeking help for postnatal depression. Australian Journal of Advanced Nursing, 19(3), 39-44.

Horowitz, J. A., \& Goodman, J. (2004). A longitudinal study of maternal postpartum depression symptoms. Research \& Theory for Nursing Practice, 18(2/3), 149-163.

Horowitz, J. A., Murphy, C. A., Gregory, K. E., \& Wojcik, J. (2011). A community-based screening initiative to identify mothers at risk for postpartum depression. Journal of Obstetric, Gynecologic, and Neonatal Nursing, 40, 52-61.

Howell, E. A., Mora, P. A., Horowitz, C. R., \& Leventhal, H. (2005). Racial and ethnic differences in factors associated with early postpartum depressive symptoms. Obstetrics \& Gynecology, 105(6), $1442-$ 1450.

Howell, E. A., Mora, P. A., \& Leventhal, H. (2006). Correlates of early postpartum depressive symptoms. Maternal And Child Health Journal, 10(2), 149-157.

Huang, Z. J., Wong, F. Y., Ronzio, C. R., \& Yu, S. M. (2007). Depressive symptomatology and mental health help-seeking patterns of U.S.- and foreign-born mothers. Maternal And Child Health Journal, 11(3), 257-267. 
Jesse, D. E. (2008). Barriers to seeking help and treatment suggestions for prenatal depressive symptoms: Focus groups with rural low income women. Issues in Mental Health Nursing, 29, 319.

Kozhimannil, K. B., Adams, A. S., Soumerai, S. B., Busch, A. B., \& Huskamp, H. A. (2011). New jersey's efforts to improve postpartum depression care did not change treatment patterns for women on medicaid. Health Affairs, 30(2), 293-301.

Lane, J. M., \& Addis, M. E. (2005). Male gender role conflict and patterns of help seeking in costa rica and the united states. Psychology of Men and Masculinity, 6(3), 155-168.

Leiferman, J. A., Dauber, S. E., Heisler, K., \& Paulson, J. F. (2008). Primary Care Physicians' Beliefs and Practices toward Maternal Depression. Journal of Women's Health, 17(7), 1143-1150.

Liberto, T. L. (Accepted for publication). Screening for depression and help seeking in postpartum women during well baby pediatric visits. Journal of Pediatric Health Care.

Library of Congress, Bill Summary and Status, $111^{\text {th }}$ Congress. (2009-2010). Melanie blocker stokes mom's opportunity to access health, education, research, and support for postpartum depression $\operatorname{act}$ (S.324.IS). Retrieved from: http://www.loc.gov/cgi-bin/query/z?c111:S.324:

MacKenzie, C. S., Gekoski, W. L., \& Knox, V. J. (2006). Age, gender, and the underutilization of mental health services: The influence of help-seeking attitudes. Aging and Mental Health, 10(6), 574582.

Mayberry, L. J., Horowitz, J. A., \& Declercq, E. (2007). Depression symptom prevalence and demographic risk factors among U.S. women during the first 2 years postpartum. JOGNN: Journal of Obstetric, Gynecologic, \& Neonatal Nursing, 36(6), 542-549.

McCarthy, M., \& McMahon, C. (2008). Acceptance and experience of treatment for postnatal depression in a community mental health setting. Health Care for Women International, 29(6), 618-637. 
McGarry, J., Kim, H., Sheng, X., Egger, M., \& Baksh, L. (2009). Postpartum depression and help-seeking behavior. Journal of Midwifery \& Women's Health, 54(1), 50-56.

Moses-Kolko, E. L., \& Roth, E. K. (2004). Antepartum and postpartum depression: Healthy mom, healthy baby. Journal of the American Medical Women's Association, 59, 181-191.

Munro, B. H. (2005). Statistical Methods for Health Care Research (5th Edition ed.): Lippincott Williams \& Wilkins.

Murray, L., \& Cooper, P. J. (1997). Effects of postnatal depression on infant development. Archives of Disease in Childhood, 77(2), 99-101.

O'Hara, M. W., \& Swain, A. M. (1996). Rates and risk of postpartum depression: A meta-analysis. International Review of Psychiatry, 8(1), 37-54.

Olson, A. L., Kemper, K. J., Kelleher, K. J., Hammond, C. S., Zuckerman, B. S., \& Dietrich, A. J. (2002). Primary Care Pediatricians' Roles and Perceived Responsibilities in the Identification and Management of Maternal Depression. Pediatrics, 110(6), 1169.

Oppo, A., Mauri, M., Ramacciotti, D., Camilleri, V., Banti, S., Borri, C., et al. (2009). Risk factors for postpartum depression: The role of the postpartum depression predictors inventory-revised. Archives of Women's Mental Health, 12, 239-249.

Outram, S., Murphy, B., \& Cockburn, J. (2004). Factors associated with accessing professional help for psychological distress in midlife australian women. Journal of Mental Health, 13(2), 185-195.

Pallant, J. (2005). SPSS survival manual: A step by step guide to data analysis using SPSS version 12 (2nd ed.): McGraw Hill.

Perfetti, J., Clark, R., \& Fillmore, C. (2004). Postpartum depression: Identification, screening, and treatment. Wisconsin Medical Journal, 103(6), 56-63. 
Price, S. K., \& Proctor, E. K. (2009). A rural perspective on perinatal depression: Prevalence, correlates, and implications for help seeking among low income women. The Journal of Rural Health, 25(2), 158-166.

Riecher-Rossler, A., \& Hofecker Fallahpour, M. (2003). Postpartum depression: do we still need this diagnostic term? Acta Psychiatrica Scandinavica. Supplementum(418), 51-56.

Righetti-Veltema, M., Bousquet, A., \& Manzano, J. (2003). Impact of postpartum depressive symptoms on mother and her 18-month-old infant. European Child \& Adolescent Psychiatry, 12(2), 75-83.

Roness, A., Mykletun, A., \& Dahl, A. A. (2005). Help seeking behavior in patients with anxiety disorder and depression. Acta Psychiatrica Scandinavica, 111, 51-58.

Segal, D. L., Coolidge, F. L., Mincic, M. S., \& O'Riley, A. (2005). Beliefs about mental illness and willingness to seek help: A cross sectional study. Aging and Mental Health, 9(4), 363-367.

Shaw, E., Levitt, C., Wong, S., \& Kaczorowski, J. (2006). Systematic Review of the Literature on Postpartum Care: Effectiveness of Postpartum Support to Improve Maternal Parenting, Mental Health, Quality of Life, and Physical Health. Birth: Issues in Perinatal Care, 33(3), 210-220.

Smith, J. P., Tran, G. Q., \& Thompson, R. D. (2008). Can theory of planned behavior help explain men's psychological help seeking? Evidence for a mediation effect and clinical implications. Psychology of Men and Masculinity, 9(3), 179-192.

Tabachnick, B. G., \& Fidell, L. S. (2007). Using Multivariate Statistics (5th ed.): Allyn and Bacon.

Thome, M. (2003). Severe postpartum distress in icelandic mothers with difficult infants: A follow up study on their health care. Scandanavian Journal of Caring Science, 17, 104-112.

Thompson, A., Hunt, C., \& Issakidis, C. (2004). Why wait? Reasons for delay and prompts to seek help for mental health problems in an australian clinical sample. Social Psychiatry and Psychiatric Epidemiology, 39, 810-817. 
Ugarriza, D. N., \& Robinson, M. K. (1997). Assessment of postpartum depression: a review of the research. Online Journal of Knowledge Synthesis for Nursing, 4(doc 6), no pagination.

Vogel, D. L., Wade, N. G., Wester, S. R., Larson, L., \& Hackler, A. H. (2007). Seeking help from a mental health professional: The influence of one's social network. Journal of Clinical Psychology, 63(3), 233-245.

Vogel, D. L., \& Wester, S. R. (2003). To seek help or not to seek help: The risks of self-disclosure. Journal of Counseling Psychology, 50, 351-361.

Vogel, D. L., Wester, S. R., Wei, M., \& Boysen, G. A. (2005). The role of outcome expectations and attitudes on decisions to seek professional help. Journal of Counseling Psychology, 52(4), 459470.

Wang, J., Patten, S. B., Williams, J. V., Currie, S., Beck, C. A., Maxwell, C. J., et al. (2005). Help seeking behaviors of individuals with mood disorders. Canadian Journal of Psychiatry, 50(10), 652-659.

Webster, J., Pritchard, M. A., Linnane, J. W. J., Roberts, J. A., Hinson, J. K., \& Starrenburg, S. E. (2001). Postnatal depression: Use of health services and satisfaction with health-care providers. Journal of Quality in Clinical Practice, 21(4), 144-148.

Weinberg, M. K., \& Tronick, E. Z. (1998). Emotional characteristics of infants associated with maternal depression and anxiety. Pediatrics, 102, 1298-1305.

Whittemore, R., \& Knafl, K. (2005). The integrative review: Updated methodology. Journal of Advanced Nursing, 52(5), 546-553.

Whitton, A., Warner, R., \& Appleby, L. (1996). The pathway to care in post-natal depression: women's attitudes to post-natal depression and its treatment. The British Journal Of General Practice: The Journal Of The Royal College Of General Practitioners, 46(408), 427-428.

Wiley, C. C., Burke, G. S., Gill, P. A., \& Law, N. E. (2004). Pediatricians views of postpartum depression: A self-administered survey. Archives of Women's Mental Health, 7(4), 231-236. 
Wilson, C. J., Deane, F. P., \& Ciarrochi, J. (2005). Measuring help seeking intentions: Properties of teh general help seeking questionnaire. Canadian Journal of Counseling, 39(1), 15-28.

Woolhouse, H., Brown, S., Krastev, A., Perlen, S., \& Gunn, J. (2009). Seeking help for anxiety and depression after childbirth: results of the Maternal Health Study. Archives of Women's Mental Health, 12(2), 75-83. 


\section{Appendix A}

\section{Research Study Cover Letter}

August 3, 2010

Dear Participant,

This letter is a request for you to take part in a research study to identify depressive symptoms and attitudes toward help seeking in postpartum women during the first year after birth. This study is being conducted by Terri L. Liberto, a PhD student in the nursing department at West Virginia University. The study is being conducted under the supervision of Dr. Cynthia A. Persily, Associate Dean for Academic Affairs. Your participation in this study is greatly appreciated and will take approximately 10-15 minutes to fill out the attached two questionnaires and information sheet.

Your involvement in this study will be kept confidential as legally possible. There will be no personal information included on the questionnaires or information sheet so the results that are reported will not be associated with any individual. You must be 18 years of age or older to participate in this study. Your participation in this study is completely voluntary. You may discontinue completion of the questionnaires at any time. Your office visit will not be affected if you participate or decide to withdraw from participation. Acknowledgement of this study is on file at West Virginia University's Institutional Review Board.

I hope that you will participate in this research study, as it could be very beneficial in determining the incidence and severity of depressive symptoms and the attitudes toward help seeking in postpartum women. Thank you very much for your time. Should you have any questions about this letter or the research project, please feel free to contact Terri Liberto at 412-389-7091 or by email tliberto@mix.wvu.edu or Dr. Cynthia Persily at 304-347-1253 or by email at cpersily@hsc.wvu.edu.

Thank you for your time and help with this research study. You will receive a referral list for postpartum depression support services after completion of the surveys.

Sincerely,

Terri L. Liberto, MSN, RN 


\section{Appendix B}

\section{BACKGROUND INFORMATION}

Mother's Age:
Number of Children:

Marital Status: Single Married Divorced Widowed Living with partner

Race/Ethnic Group: White Black/African American Hispanic/Latino Asian American Indian/Alaskan Native Native Hawaiian/Pacific Islander

Infant Feeding Method: Breastfeeding Bottle Feeding Breast and Bottle Are you satisfied with your infant feeding method? yes No

Educational Level: Less than high school High school graduate Some College Four year college degree or more

Have you ever been told by a doctor, nurse, or other health professional that you have a depressive disorder: Yes No

Partner/Family Support: Please rate the support of your partner/family with "1" indicating no support and " 5 " indicating that your partner/family is extremely supportive. Circle the correct response.

1

2

3

4

5

Have you sought care or treatment or made an appointment with a health care professional for depressive symptoms since the birth of your baby?

Yes No 


\section{Appendix C:}

\section{Postpartum Depressive Screening Scale (PDSS)}

Below is a list of statements describing how a mother may be feeling after the birth of her baby. Please indicate how much you agree or disagree with each statement. In completing the questionnaire, please circle the answer that best describes how you have felt over the past 2 weeks. Read each item carefully. Then circle the number that best fits your answer. Please give only one response for each statement, using the following scale:

$\begin{array}{ccccc}1 & 2 & 3 & 4 & 5 \\ \begin{array}{c}\text { Strongly } \\ \text { Disagree }\end{array} & \text { Disagree } & \begin{array}{c}\text { Neither Agree } \\ \text { nor Disagree }\end{array} & \text { Agree } & \begin{array}{c}\text { Strongly } \\ \text { Agree }\end{array}\end{array}$

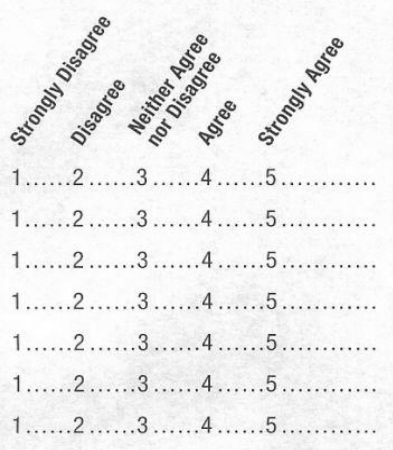

4

If you wish to change your response, completely mark through your first response with an " $\mathbf{X}$." Then circle the response that best fits your new choice.

\section{During the past 2 weeks,}

1. I had trouble sleeping even when my baby was asleep.

2. I got anxious over even the littlest things that concerned my baby.

3. I felt like my emotions were on a roller coaster.

4. I felt like I was losing my mind.

5. I was afraid that I would never be my normal self again.

6. I felt like I was not the mother I wanted to be.

7. I have thought that death seemed like the only way out of this living nightmare. Stop here if you were asked to complete only the Short Form.

$1 \ldots \ldots 2 \ldots \ldots 3 \ldots . \ldots 4 \ldots . \ldots \ldots \ldots \ldots . \quad 8$. I lost my appetite.

$1 \ldots \ldots 2 \ldots \ldots 3 \ldots . . \ldots \ldots 5 \ldots \ldots \ldots . \quad 9 . \quad$ I felt really overwhelmed.

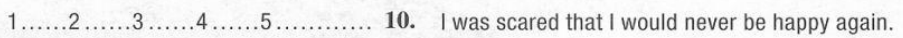

$1 \ldots \ldots 2 \ldots \ldots 3 \ldots . \ldots . \ldots 5 \ldots \ldots \ldots .11$. I could not concentrate on anything.

$1 \ldots \ldots .2 \ldots \ldots 3 \ldots . \ldots \ldots+\ldots \ldots \ldots \ldots .12$. I felt as though I had become a stranger to myself.

$1 \ldots \ldots 2 \ldots \ldots 3 \ldots . \ldots \ldots .5 \ldots \ldots \ldots .13$. I felt like so many mothers were better than me.

$1 \ldots \ldots 2 \ldots \ldots 3 \ldots . \ldots .5 \ldots \ldots \ldots \ldots .14$. I started thinking that I would be better off dead.

$1 \ldots \ldots 2 \ldots \ldots 3 \ldots . \ldots . . \ldots \ldots \ldots \ldots .15$. I woke up on my own in the middle of the night and had trouble getting back to sleep.

$1 \ldots \ldots 2 \ldots \ldots 3 \ldots . \ldots 4 \ldots 5 \ldots \ldots \ldots .16$. I felt like I was jumping out of my skin.

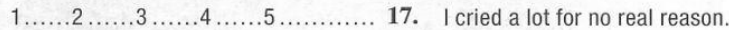

$1 \ldots \ldots .2 \ldots \ldots 3 \ldots . . . \ldots .5 \ldots \ldots \ldots .18$. I thought I was going crazy.

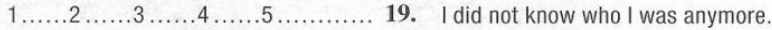

$1 \ldots \ldots .2 \ldots \ldots 3 \ldots . . \ldots . .5$

20. I felt guilty because I could not feel as much love for my baby as I should.

$1 \ldots \ldots 2 \ldots \ldots 3 \ldots . . . . . .5$

21. I wanted to hurt myself.

$1 \ldots \ldots 2 \ldots . .3 \ldots . . \ldots .5$

22. I tossed and turned for a long time at night trying to fall asleep.

$1 \ldots \ldots 2 \ldots \ldots 3 \ldots . . \ldots . . .5$

23. I felt all alone.

$1 \ldots \ldots 2 \ldots \ldots .3 \ldots . . .4 \ldots . .5$

24. I have been very irritable.

$1 \ldots \ldots 2 \ldots \ldots 3 \ldots . .4 \ldots \ldots 5$

25. I had a difficult time making even a simple decision.

$1 \ldots \ldots 2 \ldots \ldots 3 \ldots \ldots 4 \ldots \ldots 5$

26. I felt like I was not normal.

$1 \ldots \ldots 2 \ldots \ldots 3 \ldots . . \ldots . . .5 \ldots$

27. I felt like I had to hide what I was thinking or feeling toward the baby.

$1 \ldots \ldots 2 \ldots \ldots 3 \ldots . . .4 \ldots 5$

28. I felt that my baby would be better off without me.

$1 \ldots \ldots 2 \ldots \ldots 3 \ldots . .4 \ldots . .5 \ldots$

2. I knew I should eat but I could not.

$1 \ldots \ldots .2 \ldots \ldots 3 \ldots . .4 \ldots . .5$

30. I felt like I had to keep moving or pacing.

$1 \ldots \ldots 2 \ldots \ldots 3 \ldots . . \ldots . . .5$

31. I felt full of anger ready to explode.

$1 \ldots \ldots 2 \ldots \ldots 3 \ldots . . \ldots .5$

32. I had difficulty focusing on a task

$1 \ldots \ldots 2 \ldots \ldots 3 \ldots .4 \ldots . .5$

33. I did not feel real.

$1 \ldots \ldots .2 \ldots \ldots 3 \ldots . .4 \ldots \ldots 5$

34. I felt like a failure as a mother.

$1 \ldots \ldots .2 \ldots \ldots 3 \ldots . .4 \ldots . .5 \ldots$

35. I just wanted to leave this world. 


\section{Appendix D}

\section{Attitudes Toward Seeking Professional Psychological Help Short Form (ATSPPH-SF)}

Please check the appropriate box for each statement.

\begin{tabular}{|c|c|c|c|c|}
\hline Item & Agree & $\begin{array}{l}\text { Partly } \\
\text { Agree }\end{array}$ & $\begin{array}{l}\text { Partly } \\
\text { Disagree }\end{array}$ & Disagree \\
\hline $\begin{array}{l}\text { 1. If I believed I was experiencing severe } \\
\text { depression, my first inclination would be to } \\
\text { get professional attention. }\end{array}$ & & & & \\
\hline $\begin{array}{l}\text { 2. The idea of talking about problems with a } \\
\text { psychologist strikes me as a poor way to get } \\
\text { rid of emotional conflicts. }\end{array}$ & & & & \\
\hline $\begin{array}{l}\text { 3. If I were experiencing a serious emotional } \\
\text { crisis at this point in my life, I would be } \\
\text { confident that I could find relief in } \\
\text { psychotherapy. }\end{array}$ & & & & \\
\hline $\begin{array}{l}\text { 4. There is something admirable in the attitude } \\
\text { of a person who is willing to cope with her } \\
\text { conflicts and fears without resorting to } \\
\text { professional help. }\end{array}$ & & & & \\
\hline $\begin{array}{l}\text { 5. I would want to get psychological help if I } \\
\text { were worried or upset for a long period of } \\
\text { time. }\end{array}$ & & & & \\
\hline $\begin{array}{l}\text { 6. I might want to have psychological } \\
\text { counseling in the future if I experienced } \\
\text { depressive symptoms. }\end{array}$ & & & & \\
\hline $\begin{array}{l}\text { 7. A person with an emotional problem is not } \\
\text { likely to solve it alone; she is likely to solve it } \\
\text { with professional help. }\end{array}$ & & & & \\
\hline $\begin{array}{l}\text { 8. Considering the time and expense involved } \\
\text { in psychotherapy, it would have doubtful } \\
\text { value for a person like me. }\end{array}$ & & & & \\
\hline $\begin{array}{l}\text { 9. A person should work out her own } \\
\text { problems; getting psychological counseling } \\
\text { would be a last resort. }\end{array}$ & & & & \\
\hline $\begin{array}{l}\text { 10. Personal and emotional troubles, like many } \\
\text { things, tend to work out by themselves. }\end{array}$ & & & & \\
\hline
\end{tabular}




\section{Appendix E}

\section{List of Postpartum Depression Support Services}

Thank you for your participation in this study. If you are experiencing any depressive symptoms please contact your primary care physician, pediatrician, obstetrician or one of the resources below for further assistance.

Postpartum Depression Support (PPD)

http://www.ppdsupportpage.com

Postpartum Support International

http://www.postpartum.net

Saint Clair Hospital: Baby Steps (Postpartum Support Group)

Baby Steps is a support group to assist new and expecting mothers dealing with the emotional transitions of pregnancy and motherhood. New and expecting mothers are invited to attend monthly meetings to learn information about postpartum depression and gain useful tools to help cope with mood disturbances associated with pregnancy and postpartum. Baby Steps is offered once a month in the evening at Christ United Methodist Church, 44 Highland Road, Bethel Park. Please call 412.942.5882 for additional information.

UPMC Magee Women's Hospital: Depression after Delivery (DAD) Support group for mothers with depression

1-800-944-4PPD 1-800-944-4773 


\section{Appendix F}

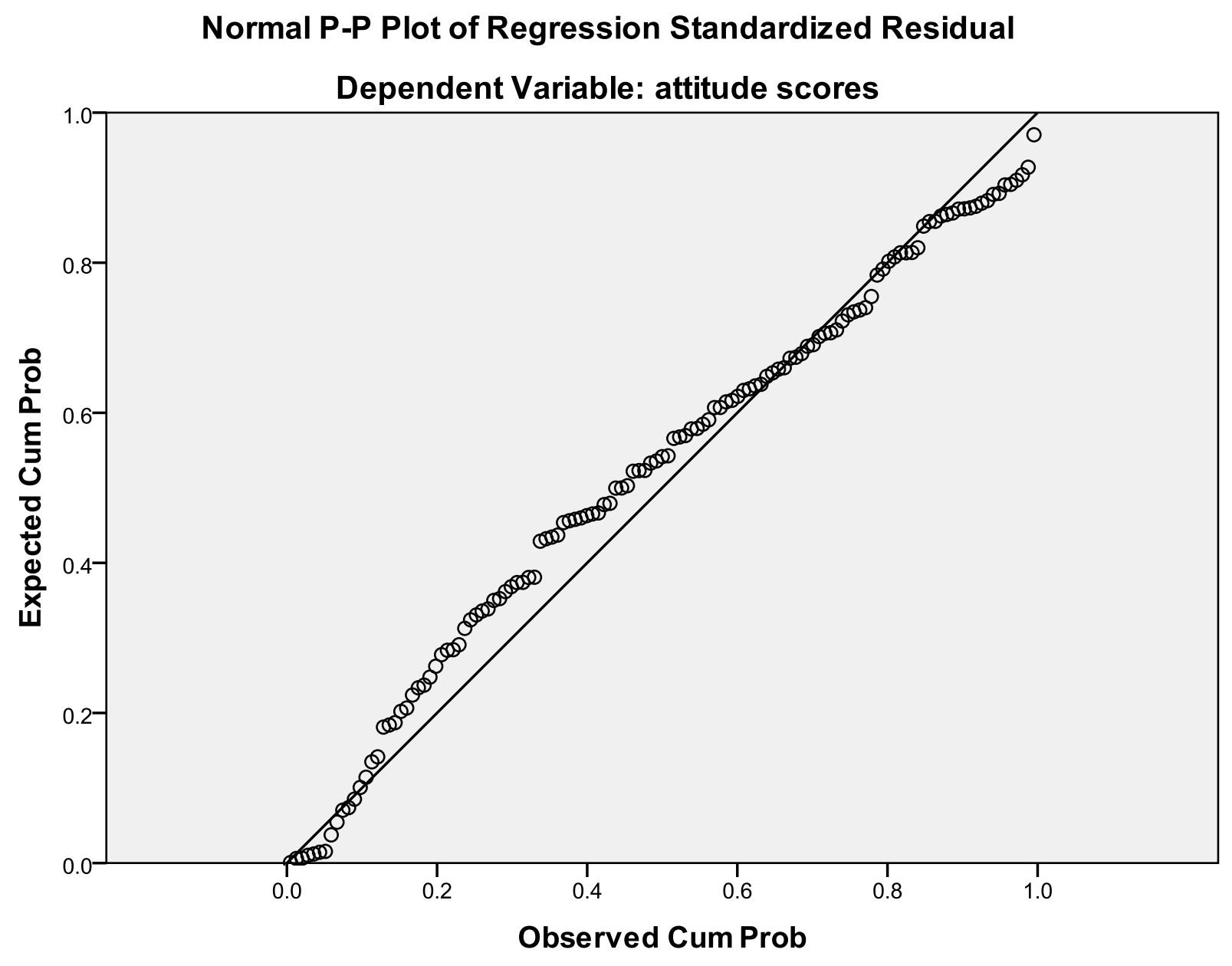




\section{Appendix G}

\section{Scatterplot}

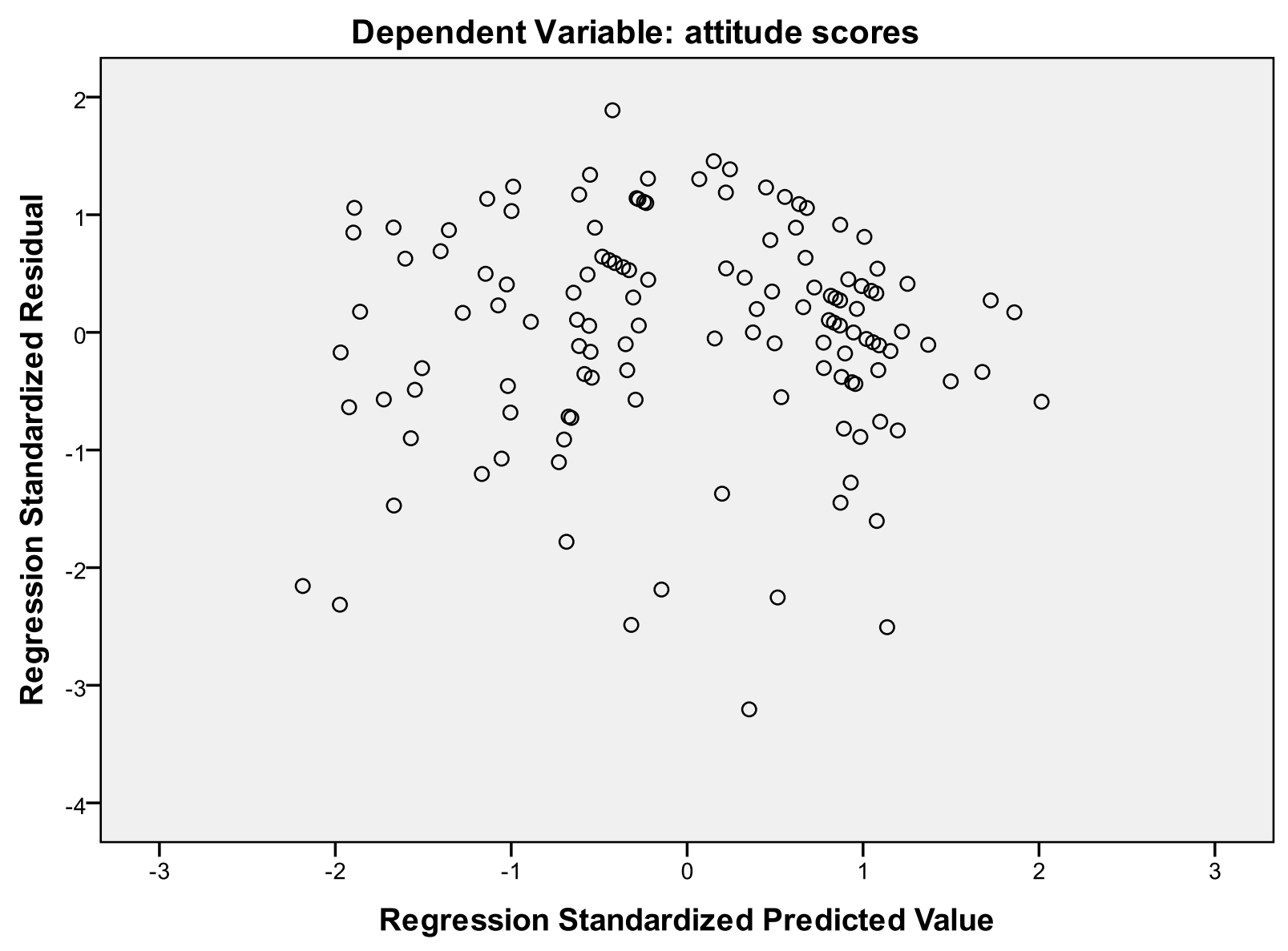

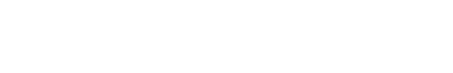

Hagen 